\title{
El "Nunca Más" uruguayo. Política ritual hacia el pasado reciente en el gobierno del Frente Amplio
}

\author{
The "Never Again" Uruguayan. Ritual policy towards the recent past in the \\ Frente Amplio government
}

Álvaro de Giorgi *

\begin{abstract}
Resumen: Este artículo se interesa por el vínculo entre las artes de la dramaturgia y la política contemporánea. Plantea una deconstrucción desde la antropología política de un ritual de Estado promovido desde el primer gobierno nacional del Frente Amplio respecto al denominado pasado reciente. Específicamente aborda un ritual conmemorativo llamado "Día del Nunca Más" impulsado por el presidente Tabaré Vázquez en el que procuró reconvertir la conmemoración patriótica del nacimiento del prócer nacional José Artigas en un ritual de renacimiento y reconciliación de la nación para poner fin a las heridas aún abiertas del pasado reciente representado como pecado fratricida. Se analizan los mitos subyacentes y las secuencias performáticas básicas que estructuran este ritual conmemorativo en el montaje de sus cuatro ediciones efectuadas entre 2007 al 2011.
\end{abstract}

Palabras clave: pasado reciente, Día del Nunca Más, ritual político, ritual de reconciliación

\begin{abstract}
This article`s main interest is the link between the dramaturgy arts and contemporary politics. It proposes a deconstruction from the political anthropology perspective of a state ritual promoted since the Frente Amplio's first national government with respect to the so-called recent past. It specifically addresses a commemorative ritual called "Day of the Never Again" promoted by President Tabaré Vázquez in which he sought to reconvert the patriotic commemoration of the birth of the national hero José Artigas in a ritual of the nation`s rebirth and reconciliation to end the still open wounds from the recent past represented as fratricidal sin. The underlying myths and the basic performance sequences that structure this commemorative ritual in the assembly of its four editions carried out between 2007 and 2011 are analyzed.
\end{abstract}

Keywords: recent past, Day of the Never Again, political ritual, ritual of reconciliation

Recibido: 12 diciembre 2017

Aceptado: 2 febrero 2018

\footnotetext{
* Uruguayo. Doctor en Ciencias Sociales, Licenciado en Antropología Social. Profesor agregado del Centro Universitario Regional del Este, Universidad de la República. Ese artículo es resultado del proyecto de investigación "Ritos políticos tradicionales del Uruguay contemporáneo", dirigido por el autor entre 04. 2015 y 04. 2017, I+D CSIC-UDELAR. Email: adegiorgi@ cure.edu.uy
} 


\section{Introducción}

El 19 de junio es un feriado nacional, denominado "Natalicio", que conmemora el nacimiento del prócer José Artigas el 19 de junio de 1764. En el año 2007 este ritual conmemorativo pasó a denominarse "Día del Nunca Más" (DNM). Su localización escenográfica, su guión, el papel desempeñado por los actores centrales, secundarios y espectadores, y la gestualidad pública desplegada por éstos, también se transformaron. Este conjunto de resignificaciones fue impulsado por el presidente Tabaré Vázquez, del Frente Amplio (FA), coalición política de izquierda que por primera vez en la historia accedió al gobierno nacional en 2005. El nuevo nombre también poseía una significación preexistente. En el Cono Sur el lema "Nunca Más" estaba -y continúa estando- estrechamente conectado a la condena al terrorismo de Estado de las dictaduras de los años setenta, popularizado por el título que dio nombre al informe de la CONADEP de Argentina en $1984^{1}$ y que fuera incorporado como propio por las organizaciones de derechos humanos uruguayas. Sin embargo, este sentido no fue el que le asignó Vázquez, puesto que privilegió utilizar reiteradamente la expresión "nunca más un hermano contra otro hermano" y definir como meta central de su propuesta el alcanzar la "reconciliación nacional" respecto al pasado reciente. $^{2}$

El legado problemático de este pasado no era algo nuevo para el Uruguay postdictadura. Hasta entonces habían existido dos posiciones básicas. Por un lado, quienes afirmaban que ese pasado estaba laudado y no reconocían la existencia de una herencia traumática -visión del centro liberal y la derecha, característica de los partidos Colorado (PC) y Nacional (PN) y las Fuerzas Armadas-. Por el otro, quienes sostenían -desde la izquierda- que persistía una profunda herida abierta en la sociedad uruguaya al no haber implementado el Estado una política de justicia transicional hacia el terrorismo de Estado dictatorial; posición tradicionalmente compartida por el FA, organismos de derechos humanos y otros movimientos sociales como el sindical y estudiantil. ${ }^{3}$

\footnotetext{
${ }^{1}$ Nunca Más. Informe de la Comisión Nacional sobre la desaparición de personas, Buenos Aires, EUDEBA, $1^{a}$ edición, 1984. Véase al respecto Emilio Crenzel, La historia política del Nunca Más. La memoria de las desapariciones en Argentina, Buenos Aires, Siglo XXI editores, 2008.

${ }^{2}$ Convencionalmente -tanto en la academia como en el debate público- se denomina "pasado reciente" al período histórico comprendido desde inicios de los años sesenta hasta mediados de los ochenta. Se asocia a un pasado de gran conflictividad política. No refiere solamente al terrorismo de Estado implementado entre 1973 y 1985 sino que incluye a la década previa en que además de represión estatal hubo violencia política proveniente de la sociedad civil -de organizaciones guerrilleras de izquierda y grupos parapoliciales de extrema derecha-.

${ }^{3}$ Cuando integro en el mismo campo ideológico de "izquierda" a partidos políticos y movimientos sociales en relación al tema de las violaciones a los derechos humanos en dictadura, no significa que no haya autonomía entre ellos. Cuando se hace mención al FA como la izquierda partidaria no se desconoce la existencia de otras expresiones políticas menores durante la post-dictadura, tales como el Nuevo Espacio -partido de centroizquierda que se escindió en 1989 y luego se reintegró al FA en 2004- o Unidad Popular -de izquierda "radical"- fundada en 2013. Madres y Familiares de Uruguayos Detenidos Desaparecidos (MFUDD) y el Servicio Paz y Justicia (SERPAJ) son las dos organizaciones de derechos humanos más relevantes. En el caso de otros movimientos sociales, destacan la central sindical (PIT-CNT) y el gremio estudiantil universitario (FEUU).
} 
La iniciativa del DNM estuvo precedida por un tibio giro desarrollado en las políticas estatales de justicia transicional cuando el gobierno del presidente Jorge Batlle (2000-2005) flexibilizó la férrea impunidad de los primeros quince años post-dictadura al considerar la demanda de verdad sobre los casos de desaparición forzada. Durante sus primeros veinte meses de gobierno Tabaré Vázquez intensificó esta apertura al promover medidas más enfáticas en relación a la verdad y habilitar la justicia para algunas causas, decisiones que tuvieron un gran impacto público. Sin embargo, el DNM pareció ser el fin de ese impulso. Por el modo en qué fue propuesto y justificado y por las puestas en escena de sus ediciones implementadas entre 2007 al 2010, este ritual conmemorativo presenta más vínculos con la tradición discursiva del pasado reciente asociada a la derecha, que a la posición histórica del FA. Tuvo una vida relativamente efímera. Ante críticas y falta de apoyo de diversos actores fue relegado al olvido. Incluso, en el actual gobierno (20152020) Vázquez retornó a la presidencia, pero no lo reimpulsó pese a que continúa vigente. Pese a su breve trayectoria, fue muy intenso y peculiar en su género: es el único ritual conmemorativo estatal relativo al pasado reciente creado durante la post-dictadura; su imbricación a una "fecha patria" y a la mayor deidad del credo nacionalista uruguayo es muy significativa; procuró integrar narrativas muy diferentes -y hasta contrapuestas- sobre lo ocurrido en el pasado reciente en un mismo acto. Estos atributos motivaron el interés por investigar este ritual político.

El olvido del gobierno sobre este evento ha sido acompañado en general por la academia. Los estudios sobre memoria e historia reciente en Uruguay constituyen un campo académico en expansión en las últimas décadas. Pero la mayor investigación se ha concentrado en temas sobre los años sesenta y la dictadura y no tanto en las luchas por la memoria del pasado reciente en la post-dictadura, y menos aún sobre los gobiernos frenteamplistas. ${ }^{4}$ En la coyuntura del lanzamiento del DNM algunos estudios específicos abordaron aspectos puntuales del mismo, pero en trabajos de más largo alcance, como la literatura dedicada a hacer un balance sobre las luchas por la memoria y/o la política de justicia transicional del caso uruguayo al cumplirse tres décadas de post-dictadura, no se menciona. ${ }^{5} \mathrm{Mi}$ interés sobre el tema proviene de mi especialización en antropología política. La política sigue siendo un tema de interés ciudadano en la esfera pública uruguaya, y acompasando esto, la politología domina el área de las ciencias sociales en la academia nacional. Pero los estudios sobre prácticas rituales de la política nacional alcanzan a contarse con los dedos de una mano. ${ }^{6}$ Profundizar el conocimiento sobre la

\footnotetext{
${ }^{4}$ Véase al respecto http://www.geipar.udelar.edu.uy, página web del Grupo de estudios interdisciplinarios sobre pasado reciente (GEIPAR) de la Universidad de la República.

5 Refiero a textos como Eugenia Allier Montaño "De historias y memorias sobre el pasado reciente en Uruguay: treinta años de debates”, en Caravelle, 104, 2015, 133-150; Francesca Lessa, “ ¿Justicia o impunidad? Cuentas pendientes a treinta años del retorno a la democracia", ILCEA 26, págs. 1-12, Université de Grenoble, 2016. La excepción es Aldo Marchesi y Peter Winn, "Uruguay: los tiempos de la memoria" en No hay mañana sin ayer, Peter Winn, Steve Stern, Federico Lorenz y Aldo Marchesi (editores), Montevideo, Banda Oriental, pags 121-204, 2014, aunque le dedica pocas líneas y no aborda la dimensión performática que se privilegiará aquí.

6 Analicé la política ritual de la transición democrática en tres capítulos del libro Álvaro de Giorgi, Sanguinetti. La otra historia del pasado reciente, Editorial Fin de Siglo, Montevideo, 2014. Para otro período, en clave histórico-antropológica, Silvina Merenson dedica un capítulo al estudio de las "marchas cañeras" de
} 
política vernácula desde el cruce entre la política y el simbolismo ritual constituye entonces otra meta importante de este artículo.

En la teoría social, sabemos desde Durkheim, sobre la importancia de los rituales para el reforzamiento del lazo social. Como sostiene David Kerstel "no puede existir política sin simbolismo, y en la construcción y disputa de los símbolos, el ritual ejerce un papel central. Proporciona un medio de tornar palpable aquello que, de otro modo, no puede ser visto". ${ }^{7}$ Los estudios antropológicos contemporáneos sobre el ritual político se deslizan cada vez más hacia un campo transdisciplinario, entrelazado con los estudios sobre teatralidades sociales y con los performances studies. En particular me interesa profundizar en la analogía entre la política y el teatro, y en el desempeño del político -en este caso el presidente Vázquez- no solamente como "actor" sino también como "productor ejecutivo" de la obra "Día del Nunca Más".

El primer apartado de este artículo repasa cómo se procesó la problemática del pasado reciente durante la post-dictadura previo al DNM, en tres etapas: entre 1985 al 2000, donde imperó la "pacificación nacional" sobre los reclamos de "verdad y justicia"; entre el 2000 a fines del 2006 donde ocurrió una apertura hacia ambas demandas desde las políticas estatales, y de fines del 2006 a junio del 2007, cuando se discute públicamente el proyecto conmemorativo. Todo ritual contiene una serie de sentidos codificados que son puestos en acción. El segundo apartado repasa los soportes míticos subyacentes que pueden identificarse en el DNM al considerar su nombre, la fecha seleccionada y los términos y metáforas en los que enmarcó la justificación para su creación el presidente Vázquez. Se complementa con una revisión somera de antecedentes -nacionales e internacionales- de rituales políticos representativos de estos sentidos codificados, estas creencias subyacentes. El tercer apartado privilegia el análisis de los montajes escenificados colocando el foco en sus dos secuencias más significativas: la apertura y el desfile. En el último apartado se exponen las conclusiones.

\section{Los legados de la post-dictadura y el camino hacia el DNM}

\section{De 1985 al 2000: pacificación o justicia y el relato de la democracia modelo}

Desde 1973 hasta mediados de los ochenta Uruguay sufrió una dictadura militar que practicó sistemáticamente el terrorismo de Estado. El $1^{\circ}$ de marzo de 1985 , Julio Sanguinetti, del sector batllista del PC, asumió como primer presidente democrático en elecciones condicionadas, resultado del pacto de salida acordado con los militares. El mayor reto de su gobierno era consolidar la transición a la democracia, problemática que planteaba entre sus principales desafíos cómo tramitar las violaciones a los derechos humanos acaecidas en la dictadura. Luego de muchas dilatorias y en un contexto de amenaza de desacato institucional por parte del Ejército que presionó para impedir

los años sesenta, concebidas como rituales, en Los peludos. Cultura, política y nación en los márgenes del Uruguay, Gorla, Buenos Aires, 2016.

7 David Kertzer, "Rituais políticos e a transformação do Partido Comunista Italiano", Horizontes Antropológicos, 15, 15-36, Porto Alegre, 2001. 
inminentes juicios a militares, el parlamento aprobó en diciembre de 1986 la Ley de Caducidad de la pretensión punitiva del Estado con los votos del partido gobernante y de la mayoría del PN y la oposición del FA y un sector minoritario del PN. ${ }^{8}$ Esta ley oficializó la amnistía a los militares. ${ }^{9}$ Su influencia no determinó solamente la transición en los ochenta sino que delimitó también los márgenes de acción en materia de justicia transicional para las décadas siguientes. ${ }^{10}$ Luego de su aprobación organizaciones sociales, el FA y un sector del PN convocaron a un referéndum para su derogación pero resultó negativo, siendo convalidada por el voto directo ciudadano en abril de 1989.

La impunidad se cimentó en una construcción ideológica muy sólidamente articulada por la elite política que condujo la transición encabezada por el presidente Sanguinetti. Sus postulados centrales fueron los siguientes. En primera instancia, el pasado reciente se representó como una gran anomalía extrínseca, un accidente histórico contingente, completamente ajeno a la historia e identidad uruguayas. La "esencia" nacional radicaba -según esta perspectiva- en su extraordinario apego a la democracia. Como contraparte el pasado reciente estuvo dominado por la "violencia". Al recuperarse la institucionalidad democrática, se planteó que era imperioso priorizar la estabilidad y "mirar hacia adelante" como forma de evitar "retroceder hacia el pasado de la violencia". En segundo lugar, la idea de pasado reciente violento no se limitó a la dictadura, sino que comprendió también sus años previos: la década del sesenta. Una figuración dual de la violencia; lo que en Argentina se ha denominado "teoría de los dos demonios"11. El gobierno de Sanguinetti -apropiándose en parte de la labor previa construida durante la

\footnotetext{
${ }^{8}$ Es momento de presentar rasgos generales y cambios recientes del sistema partidario uruguayo. El PC y PN surgieron casi con el país -en 1836- por lo que se los define como "tradicionales" o "fundacionales". Conformaron un largo bipardisimo -con predominio del PC- hasta 1989. Con el surgimiento del FA interrupción de la dictadura mediante- empezó a virar hacia un sistema de tres tercios entre 1994 al 2004 y desde entonces al presente a un nuevo bipartidismo entre el FA por un lado -que ha alcanzado el $50 \%$ del electorado en las tres últimas elecciones- y los partidos tradicionales por otro, asociados en ballotage para competir con la izquierda. 2005 significó el giro histórico en el cambio de hegemonía partidaria. El FA surgió en 1971 como coalición integrada por partidos marxistas -como el Comunista y Socialista-, el partido Demócrata-Cristiano y dirigentes escindidos del PC y PN bajo el liderazgo de un prestigioso militar, el Gral. Líber Seregni. Luego del retorno a la democracia se fueron algunos sectores e incorporaron otros siendo el más significativo una fracción de ex-guerrilleros tupamaros liderada por José Mujica. Actualmente se lo considera un partido tipo catch all, con distintas corrientes internas que no presentan grandes diferencias ideológicas a su interior. El FA en su conjunto se moderó ideológicamente en forma considerable respecto a su etapa fundacional. A sus tres gobiernos se lo denomina también como la "era progresista". Ver al respecto Jaime Yaffé, Al centro y adentro. La renovación de la izquierda y el triunfo del Frente Amplio en Uruguay, Montevideo, Linardi y Risso, 2005; Constanza Moreira, Final de juego. Del bipartidismo tradicional al triunfo de la izquierda en Uruguay, Montevideo, Trilce, 2004. Adolfo Garcé y Jaime Yaffé. La era progresista, Montevideo, Fin de Siglo, 2014.

${ }^{9} \mathrm{Su}$ contenido y la forma en que fue aprobada demostraron algo evidente. La dictadura no finalizó porque fuera derrotada. Los militares habían entregado voluntariamente el poder a las autoridades civiles con la condición de que no fueran juzgados por los hechos cometidos durante la misma, que ni siquiera reconocían como delictivos.

10 Aldo Marchesi (ed.) Ley de Caducidad un tema inconcluso. Momentos, actores y argumentos (19862013), CSIC - Trilce, Montevideo, 2013.

11 Veáse al respecto Marina Franco, La 'teoría de los dos demonios': un símbolo de la posdictadura en la Argentina", Revista Contracorriente, NC State University, Vol. 11, No. 2, Winter 2014, pp. 22-52.
} 
dictadura- representó a los años sesenta como una "guerra entre bandos" y a la guerrilla como una maquinaria sanguinaria irracional. En particular, la organización guerrillera MLN-Tupamaros devino el símbolo por antonomasia de la "violencia sin sentido". Los sesenta terminaron siendo en el discurso estatal de los primeros años de la post-dictadura el pasado más condenable de todo el pasado conflictivo previo. Además de sus prácticas, el problema con la guerrilla -y por extensión, de toda la izquierda- radicaba en sus creencias, en su adhesión al credo revolucionario y el consecuente descreimiento de la democracia como valor esencial de la nación. Si el país había nacido por y para la democracia, y su extraordinaria historia así lo confirmaba, el pasado turbulento de los sesenta con su "sesentismo trasnochado" constituían su más clara antítesis por haber dado inicio a la violencia y por engendrar la semilla de dicho descreimiento. En tercer y último lugar, la violencia "sesentista" ya había sido perdonada, por ello, la otra -la menor de acuerdo a esta visión-, en la que incurrieron algunos militares, debía ser también igualmente perdonada. ${ }^{12}$ Ello implicaba un acto ecuánime, a la altura del "espíritu de tolerancia" que rige una democracia plena si quiere ser considerada tal como la uruguaya, según el discurso sanguinettista. ${ }^{13}$

Entre 1985 y 1989 la izquierda tanto política como social habían planteado el problema de las violaciones a los derechos humanos en dictadura bajo la antinomia "justicia" o "impunidad", procurando desligar las víctimas del terrorismo de Estado de su asociación con la guerrilla o los años sesenta. Pero el gobierno había planteado la herencia del pasado reciente, en otros términos: la antinomia central era entre "consolidar la pacificación" o "retornar al pasado de la violencia". Esto último más que significar una regresión al autoritarismo militar se definía fundamentalmente como el fantasma del retorno al "sesentismo". Los ochenta no podían volver a repetir lo sucedido en el pasado previo -es decir, la "guerra" de los sesenta-. Esa era su consigna. Así, las demandas de "verdad y justicia" sobre el terrorismo de Estado promovidas desde el FA y movimientos sociales fueron descalificadas como intentos de "venganza" de uno de los "bandos" en pugna y en tanto tal, partidarios de la continuidad de la "violencia". La aprobación por el referéndum de la Ley de Caducidad consolidó la interpretación del gobierno. A partir de ello ya no hubo margen posible para hablar de "justicia" o "impunidad" sino que se instaló

\footnotetext{
12 Esto requiere una explicación más detallada. El 8 de marzo de 1985 el parlamento aprobó con votos de todos los partidos una Ley de Amnistía que estableció la amnistía de los presos políticos de conciencia del régimen militar y la liberación para integrantes de organizaciones guerrilleras que habían cometido actos criminales por la conmutación de su pena. A estos últimos no se los amnistió, pero se les dio por cumplida la condena debido a las extremas condiciones de reclusión a los que habían sido sometidos. Casi dos años después, como justificación para votar la Ley de Caducidad el gobierno argumentó que si los "terroristas tupamaros" habían sido liberados era un acto de estricta justicia "perdonar por igual a los militares". El problema con esta equiparación es que mientras la primera ley amnistió mayormente a militantes sociales y políticos que nunca habían tomado las armas y liberó por las razones expuestas a los ex-guerrilleros luego de doce años de prisión, la segunda ley amnistió a militares presuntamente implicados en delitos sin previo juicio ni haber pasado un día presos.

13 Sobre el discurso sanguinettista y "ochentista" véase Álvaro de Giorgi, ob.cit.; Álvaro Rico, Cómo nos domina la clase gobernante. Orden político y obediencia social en la democracia posdictadura. Uruguay 1985-2005. Montevideo, Trilce, 2005; Gabriel Delacoste, "El ochentismo" en Álvaro de Giorgi y Carlos Demasi (coord.) El retorno a la democracia. Otras miradas, Fin de Siglo Montevideo, 21-46.
} 
un discurso único: el de la "justicia de la democracia", la que "perdonó a ambos bandos" frente a los reclamos "revanchistas" de "justicia hemipléjica". Para abril de 1989 esta contraposición se había resuelto ampliamente por esta supuesta "justicia", obra de una democracia que recobraba su excepcionalidad y carácter de "modelo", y seguiría entendiéndose así hasta el año 2000 desde las políticas estatales de los siguientes dos gobiernos, conducidos por Luis Lacalle (1990-1995) del PN y nuevamente por Sanguinetti (1995-2000).

La dictadura legó a la democracia como herencia las secuelas del terrorismo de Estado: la prisión prolongada en extremas condiciones de reclusión, la tortura, el asesinato y la desaparición forzada aplicada a sus opositores políticos. La herencia de los primeros quince años post-dictadura fue la impunidad de tales crímenes al negar la posibilidad del acceso a la verdad de lo ocurrido y menos aún de aplicar justicia. Su legado fue también la creación de una narración muy sólida, que se convirtió en hegemónica, para la cual el Uruguay retomó su esencia democrática de manera ejemplar al dejar atrás el pasado de la violencia con "espíritu tolerante" y sin "revanchismos", poniendo en práctica un acto de "verdadera justicia" frente a lo que se etiquetó como un reclamo fariseo de justicia unilateral por parte de la izquierda.

\section{Del 2000 al 2006: giro hacia la "verdad", la memoria y algo de "justicia"}

En el año 2000 se produjo un giro relativamente inesperado en la política estatal hacia el pasado reciente puesto que los colorados volvieron a gobernar el país, pero el nuevo presidente, Jorge Batlle, se mostró dispuesto a atender la demanda de verdad sobre lo ocurrido con los desaparecidos. Impulsó una comisión investigadora denominada "Comisión para la Paz". Si bien tenía limitadas potestades y recursos, y muchas de sus conclusiones fueron posteriormente cuestionadas, en su momento constituyó un gran avance al oficializar y reconocer por primera vez, a dieciocho años de finalizada la dictadura, la responsabilidad del Estado uruguayo en las desapariciones forzadas.

Al llegar el FA al gobierno nacional en marzo del 2005 los debates públicos sobre la herencia del pasado reciente no se habían sosegado con esta apertura, sino que se habían incrementado. En su primer año y medio de gobierno Vázquez no defraudó las expectativas generadas. Como acciones más destacadas, profundizó las medidas en relación a la demanda de verdad al constituir una nueva comisión investigadora oficial sobre los desaparecidos provista con recursos y metas mucho más ambiciosas que la anterior ${ }^{14} \mathrm{y}$ al habilitar la búsqueda de restos físicos de desaparecidos en predios militares y otros sitios de enterramiento clandestinos en el territorio nacional. A ello le agregó una decisión totalmente inédita en todos los gobiernos democráticos previos: la aplicación de justicia. Si bien parcial, puesto que la ley de Caducidad seguía vigente, bajo los resquicios que ésta permitía, el Poder Ejecutivo habilitó el pasaje a la justicia de causas que consideró no

14 Alvaro Rico (Coord.) Investigación histórica sobre Detenidos Desaparecidos. En cumplimiento del artículo 4 de la Ley 15.848, Montevideo, Presidencia de la República, 2007. 
comprendidas en la misma. ${ }^{15}$ Ambas medidas tuvieron un alto impacto en la esfera pública. Entre fines del 2005 y marzo del 2006 se hallaron los restos de dos ciudadanos desaparecidos. Su desenterramiento transmitido en directo por la televisión y expuesto en fotografías en primeros planos de los diarios erosionaba fuertemente el discurso de la "justicia integral de la democracia modelo" esgrimido hasta pocos años antes. En relación a la justicia, en noviembre de 2006 fueron condenados a veinte años de prisión el ex-canciller de la dictadura Juan Blanco y el ex dictador Juan Bordaberry -presidente constitucional en ejercicio en 1973 que promovió el (auto)golpe de Estado junto con los militares-, ambos civiles, por el homicidio en Buenos Aires de los ex-legisladores Zelmar Michelini y Héctor Gutiérrez Ruiz, dos víctimas emblemáticas de la dictadura. Por esas mismas fechas el Tte. Gral. Gregorio Álvarez era imputado en varias causas relativas a "reiterados delitos de desaparición forzada" ocurridas en Argentina, por lo que era inminente su procesamiento (que finalmente se concretó en diciembre 2007). En setiembre de 2006 habían sido procesados con prisión seis militares y dos policías en causas vinculadas a desapariciones de uruguayos en Argentina. Constituían el núcleo duro de oficiales que dirigieron los operativos represivos más cruentos, nombres reiterados en los testimonios de los denunciantes desde hacía décadas. ${ }^{16}$ Esta política implicó no solamente avances en el reconocimiento oficial de la verdad de lo ocurrido y en el juicio y castigo a los responsables, sino también en el plano de la memoria puesto que erosionaban fuertemente el relato autocomplaciente y negacionista de la "salida a la uruguaya" como transición modelo y a los años sesenta como lo peor del "pasado de la violencia". Nada más concreto que una osamenta con restos de ropa adheridos enterrados por años para evidenciar la existencia del terrorismo de Estado en dictadura y su impunidad posterior.

\section{La producción ejecutiva del Nunca Más}

En ese clima imperante de "fin de la impunidad" el 26 de diciembre de 2006 el presidente convocó a una conferencia de prensa para presentar su iniciativa

[el deseo] que podamos avanzar hacia el futuro en un terreno de reconciliación y de reencuentro de todos los uruguayos para que todos juntos asumamos que estos tristes y negativos hechos que han sucedido en este país nunca más vuelvan a suceder. Nunca más un hermano contra otro hermano en este país (...) fíjase el día 19 de junio de cada año como única

\footnotetext{
15 La Ley de Caducidad establecía que era el Poder Ejecutivo el que detentaba la potestad de decidir sobre qué denuncias quedaban comprendidas en la ley y cuáles no. Los gobiernos previos al 2005 entendieron que todas las denuncias se hallaban comprendidas por lo que nunca les dieron paso a la justicia ordinaria. En cambio, el gobierno de Vázquez procedió de otra manera puesto que el artículo $1^{\circ}$ definía que el Estado caducaba en su pretensión punitiva en los "delitos realizados [en el país] por móviles políticos cometidos por militares y policías entre el 27 de junio de 1973 y el 1 de marzo de 1985” por lo que la interpretación del Poder Ejecutivo conducido por Vázquez consideró no amparados los crímenes anteriores a 1973, los realizados en el exterior y los que imputaban a civiles.

${ }^{16}$ Para más detalles véase Eugenia Allier Montaño, Batallas por la memoria. Los usos políticos del pasado reciente en Uruguay, Trilce, Montevideo, 2010, p. 246 y 254-256.
} 
fecha conmemorativa de que nunca más deberán ocurrir estos episodios entre uruguayos ${ }^{17}$

El anuncio generó sorpresa y polémicas en la opinión pública, fundamentalmente desde los organismos de derechos humanos y a la interna del propio FA. De hecho, se trataba de una propuesta que no figuraba en su programa de gobierno. El malestar y los debates aumentaron a partir de otra resolución presidencial. Vázquez respaldó e hizo suya una iniciativa parlamentaria de un diputado conservador colorado que propuso una ley de reparaciones a militares y policías víctimas de la violencia guerrillera entre los años 1962 a 1976. Este proyecto de ley convalidaba la interpretación del pasado reciente tradicional a la derecha en la medida en que reconocía implícitamente la existencia de una "guerra entre dos bandos" al plantear la equiparación de sus víctimas. Organizaciones de retirados militares celebraron el hecho y legisladores del PC y PN manifestaron su satisfacción y disposición a votarlo. Un nuevo hecho agitaría más las aguas. El 18 de mayo, en el acto oficial del Día del Ejército, el Comandante en Jefe en ejercicio criticó veladamente la interpretación de la ley de Caducidad del gobierno y celebró la idea del DNM en clave de "punto final" al pasado reciente. Mientras la mayoría de la derecha político-partidaria y social rescataba al DNM, colocando el énfasis en la reconciliación, la prioridad en el futuro y la dilución de la violencia dictatorial en una violencia más general y compartida, ${ }^{18}$ las organizaciones sociales de derechos humanos y sectores políticos del propio FA exigieron un pronunciamiento más claro sobre qué sentido le asignaba el presidente a la consigna "Nunca Más" y en qué consistiría concretamente el inminente acto del 19 de junio.

Vázquez se mantuvo en silencio hasta el 4 de junio, a quince días del evento, cuando convocó a una nueva conferencia de prensa en la que hizo referencia al "terrorismo de Estado" al mismo tiempo que señaló que no estaban dadas las condiciones para realizar su idea original, por lo que concurriría solo a colocar una ofrenda floral ante la estatua de Artigas en plaza Independencia. Su tenue mención explícita al "terrorismo de Estado" produjo un realineamiento entre quienes desde marzo a junio habían adherido y quienes habían objetado la propuesta. Los primeros -sectores conservadores del PN y PC y asociaciones de retirados militares- le retiraron su apoyo porque criticaron la ausencia de una condena explícita de igual tenor al "terrorismo subversivo". Entre los segundos, algunos sectores que hasta entonces se mostraban renuentes se mostraron satisfechos y pasaron a aceptarla -como la Vertiente Artiguista- mientras que otros mantuvieron su desaprobación -como Corriente de Izquierda o el Partido Comunista-. Esto tensionó las relaciones entre el gobierno, el partido y sus fracciones internas. Las organizaciones sociales mantuvieron su postura crítica. ${ }^{19}$ Otros dirigentes políticos de sectores de centro de

\footnotetext{
17 Tabaré Vázquez, conferencia de prensa en Edificio Libertad, 26.12. 2006. Archivo presidencia.gub.uy.

${ }^{18}$ No toda la derecha celebró el proyecto conmemorativo. Los ex-presidentes Sanguinetti, Batlle y Lacalle se manifestaron decididamente en contra argumentando que la "reconciliación" ya había sido alcanzada y que esto significaba volver al pasado, además de criticar el desplazamiento del "Natalicio".

19 Mariana Iglesias, "El 'Día del Nunca Más' en Uruguay”, en Bohoslavsky, Ernesto et alter (coords.) Problemas de historia reciente del Cono Sur, Vol. 1, pp. 147-169, Buenos Aires, Prometeo/UNGS, 2010.
} 
los partidos tradicionales se abstuvieron de pronunciarse hasta el día previo a la realización del acto.

El desempeño público de Vázquez durante este intenso semestre de fines del 2006 a junio del 2007 puede ser pensado a través de la analogía entre la política y el teatro. En su forma más convencional consiste en considerar al político como un actor. Aquí propongo extenderla a otro tipo de roles inherentes al quehacer teatral, como el de productor ejecutivo de un espectáculo. Un productor ejecutivo es el profesional responsable de la supervisión de todos los aspectos del montaje de una producción teatral desde su fase de proyecto hasta su concreción final ante un público específico y en un espacio determinado. Tales actividades abarcan, por ejemplo, la selección del guión, la negociación de los derechos de adaptación de la obra, la contratación del director y los actores o la administración de la parte logística y los recursos financieros requeridos. ${ }^{20} \mathrm{En}$ algunos espectáculos este rol puede coexistir con los aspectos más creativos; es decir, una misma persona puede ser a la vez el productor ejecutivo, dramaturgo, director artístico y actor protagónico de la obra.

Sobre cómo será el acto es muy poco lo que se sabe. En principio se está en condiciones de adelantar que no se hará en Sauce, que era un acto tradicional. Las fuentes del gobierno dijeron que la idea ahora, tras los líos que despertó la iniciativa, es pasar el 19 de junio sin alharacas. Tradicionalmente en el acto de Sauce hablaba un ministro (...) En esta oportunidad, ya que no habrá discurso en Sauce, ¿hablará alguien en nombre del gobierno en la Plaza Independencia? No se sabe. Se había conformado una comisión para organizar el acto con los Ministerios de Educación y Cultura, Defensa e Interior. A poco de comenzar a trabajar esta comisión el presidente Vázquez mandó parar y disolvió esta coordinación. Y el acto pasó en todos sus términos a Presidencia de la República que fijará todos los detalles. ${ }^{21}$

Fue el presidente quien públicamente presentó el proyecto, su nombre, el libreto general con su respectivo reparto de actores, la fecha y marco escenográfico, y quien manejó los tiempos de adaptación de la idea a la puesta en escena, procurando superar los obstáculos que se fueron presentando. El mayor escollo en el caso de un ritual político con este perfil se centraba en lograr la aceptación voluntaria de los actores convocados a participar de la puesta en escena dado que -a diferencia de lo que ocurre en el teatro comercial- el productor ejecutivo no puede negociar la integración del elenco por medio de una retribución económica. A su vez, muchos de los actores convocados son también guionistas-productores de sus propias obras dramáticas ya presentes en la cartelera política nacional. En función de ello, no tendrían por qué estar dispuestos a cambiar su libreto y su papel en la representación ritual del drama del pasado trágico reciente. Como productor ejecutivo Vázquez procuró negociar la adaptación de "derechos de autor" de libretos ya preestablecidos -tales como la "teoría de los dos demonios" o la condena al terrorismo de

${ }^{20}$ Andrea Hanna, "El rol del productor en el teatro independiente. La producción es ejecutiva y algo más”, Cuadernos del Centro de Estudios en Diseño y Comunicación, 50, Año 15 2014, pp. 75-80.

${ }^{21}$ Espectador.com, "El Día del Nunca Más: una pifia del gobierno” http:www.espectador.com/politica/ 96383/el-dia-del-nunca-mas-una pifia-del gobierno. 28 de mayo de 2007. 
Estado- integrándolos a una nueva obra compuesta por fragmentos de las anteriores, devenida nueva síntesis. ${ }^{22} \mathrm{Su}$ intento de atraer a su proyecto conmemorativo a un amplio espectro de actores sociales y políticos vinculados a la temática -que se pueden esquematizar a través del eje ideológico derecha-izquierda- tales como asociaciones de retirados militares, partidos políticos tradicionales, sectores partidarios de su propia fuerza política, movimientos sociales de derechos humanos, la propia institucionalidad estatal, entre otros, se apoyó en las medidas paralelas impulsadas desde su gobierno descriptas anteriormente. Hacia la izquierda, en los planos de la verdad -búsqueda y hallazgo de desaparecidos- y justicia -procesamiento de ex-dictadores y represores emblemáticos-; hacia la derecha, integración de "sus" víctimas a la política estatal de reparación y la narración de la memoria del pasado reciente como una violencia global no limitada unívocamente al período dictatorial. Esto no fue suficiente para muchos de los actores(guionistas) convocados, aunque de todos modos la ejecución del proyecto siguió adelante sin ellos.

\section{Soportes míticos y antecedentes rituales}

\section{EI nacionalismo esencialista y la tradición del "Natalicio"}

el 19 de junio seguirá siendo el día donde los uruguayos conmemoramos el nacimiento de nuestro Prócer, Don José Gervasio Artigas. El 19 de junio es ese día, ni más ni menos. El Padre de la Patria, sí señor. Pero ese día, que es un día de encuentro de la mayoría de los uruguayos con sus raíces, debe ser también el día del compromiso a que nunca más sucedan hechos de intolerancia y violencia entre los ciudadanos uruguayos. El 19 de Junio conmemoramos el nacimiento de nuestro Prócer con el nacimiento de nuestra Patria. Por tanto, el 19 de junio es el día que tiene esencialmente el germen del surgimiento de este país, y tiene a la máxima personalidad de entre todos nosotros que nos permitirá asumir definitivamente el compromiso del Nunca Más ${ }^{23}$

El nacionalismo en su versión más esencialista constituye el credo más importante de la conmemoración tradicional del 19 de junio ${ }^{24}$. Su dogma central postula a la nación -o la patria, entendidas como sinónimos-, como una entidad ancestral definida por una configuración particular de valores espirituales que la hace única frente a otras naciones. La patria es también una comunidad de sangre y de sentimientos, antes que una relación

${ }^{22}$ Considerando en su globalidad la metáfora teatral, en lo relativo al guión y al guionista de esta nueva síntesis, es importante dejar en claro que Vázquez no actuó solo. Diverss testimonios del entorno presidencial han destacado el papel central de sus secretarios en muchas de sus iniciativas y en particular en la elaboración de los discursos de las conferencias de prensa. En este sentido, Vázquez es un gran actor, pero no un buen guionista, y la producción ejecutiva propiamente tal, estrictamente, implicó una tarea más colectiva e institucionalizada, desarrollada desde Presidencia de la República.

${ }^{23}$ Tabaré Vázquez, conferencia de prensa en Edificio Libertad, 26.12. 2006.

${ }^{24}$ La bibliografía sobre el tema es imposible de consignar aquí dada su vastedad. Solamente a título de ejemplo, como clásico sobre la nación como mitología cabe mencionar a Smith, Anthony, "The myth of the 'modern nation' and the myths of nations”, Ethnic and Racial Studies 11, v.1, 1988, pp. 1-26. 
contractual razonada. Su existencia no es puesta en cuestión, se define como natural, e imperecedera -como toda esencia-. La prueba de fe de su existencia remite a su origen -la circunstancia en que valores espirituales, territorio y habitantes se fusionaron-, por ello el mito de origen y el héroe fundacional son tan importantes en la narrativa del credo nacionalista. La nación surge en un tiempo extraordinario cuando ocurre la materialización de la esencia, al arraigar en el territorio por una serie de acciones extraordinarias protagonizadas por el héroe fundador. En el caso de Uruguay el tiempo extraordinario para este credo fue el período de revolución y luchas independentistas, y el héroe fundador, José Artigas. El héroe despierta de su letargo a la patria, al cortar de raíz, con su espada, sus dependencias anteriores enfrentando a quienes se oponían a su emancipación. La nación existe por el héroe y el héroe para la nación; por ello el héroe es el progenitor de la patria, y viceversa. El proteico espíritu nacional logra asentarse en su tierra mediante las acciones del héroe. A cambio de su sacrificio, el héroe, una vez desaparecido físicamente su cuerpo material -no totalmente, puesto que sus cenizas permanecen, guardadas- se vuelve el símbolo máximo de la esencia nacional.

A posteriori, el devenir de la historia patria comprende la reproducción por siempre de la esencia ya encarnada, que asegure su eternidad. Una vez creada, el destino de la nación dependerá del recuerdo de la epopeya heroica que hizo posible su nacimiento. Las sucesivas generaciones deberán recordar con veneración el tiempo fundacional y procurar aproximarse a continuar el legado del héroe lo más fielmente posible. Hacerse cargo de esta continuidad es tarea de los sucesivos nuevos conductores de la nación quienes procurarán representarse como sus más legítimos herederos.

Artigas falleció en 1850, su elevación a la categoría de prócer nacional indiscutible se construyó a partir del último cuarto del siglo XIX, con la primera modernización del Estado. En este contexto se crea el relato del pasado fundacional y su transformación en "el padre de la Patria". En ese período comenzó la temprana secularización de la sociedad uruguaya que termina de consolidarse con la separación de la Iglesia del Estado en la constitución de 1919. La figura de Artigas pasó a ocupar un lugar central en la nueva religión civil uruguaya. Su culto no remite exclusivamente al Estado sino que permea a toda la sociedad. Su veneración es compartida por todos los partidos políticos y las más heterogéneas organizaciones de la sociedad civil, incluso aquellas más contestatarias. En 1923 fue inaugurado su altar más grandilocuente: una gran estatua ecuestre en el centro de la Plaza Independencia de Montevideo, el más importante espacio simbólico-político nacional. ${ }^{25}$

El "Natalicio" se incorporó al calendario oficial de "fechas patrias" en 1894. Su escenificación tradicional ha sido la siguiente. Artigas vivió parte de su infancia en un pueblo cercano a Montevideo llamado Sauce. A partir de 1915 el ritual conmemorativo de su aniversario de nacimiento se institucionalizó allí. El ritual se estructura en cuatro secuencias: arribo y bienvenida local a las máximas autoridades del gobierno e invitados

${ }^{25}$ El ejemplo más nítido de la divinización de Artigas lo constituye un himno, denominado "Himno a Artigas", creado en la década del cuarenta del siglo pasado, que -en conjunto con el Himno Nacional- inicia los actos escolares y patrióticos. Sus primeras estrofas dicen: "El Padre nuestro Artigas /señor de nuestra tierra/que como un sol llevaba/la libertad en pos/Hoy es para los pueblos /el verbo de la gloria/para la historia un genio/para la Patria un Dios". 
oficiales; ofrenda floral al pie del monumento al prócer por parte de la máxima autoridad concurrente -en general el presidente de la República-; discurso verbal por parte de un integrante del Poder Ejecutivo y autoridades locales; desfile cívico-militar. Este tipo de dispositivo identitario -el ritual conmemorativo- es de gran eficacia para actualizar el vínculo entre pasado -los orígenes fundacionales- y presente. Primero, mediante la palabra. El discurso verbal del portavoz del gobierno comienza con un introito de corte "histórico" dedicado a recordar las virtudes y valores del héroe seguido de una enumeración de acciones realizadas por el gobierno en su gestión presente, expuestas como ejemplo de concreción actual del legado del prócer. La comunidad renueva su pacto con la nación al ligar el ideario y valores -más abstractos- de Artigas con hechos del presente que procuran demostrar como esos valores e ideario "eternos" se materializan en la política gubernamental. El recuerdo de la esencia inmutable que forjó la nación como entidad única se articula al balance de lo que hace el gobierno para que la nación siga progresando. Segundo, el discurso no verbal, el lenguaje por excelencia del ritual. La ofrenda inicial es un ejemplo de ello, pero para que la renovación del lazo entre el prócer y su descendencia sea completa no sólo debe involucrar a las autoridades, sino que debe ser complementada con otro tipo de performances que involucren también al "pueblo". En una pequeña localidad donde este evento constituye el día más importante del año, la concurrencia popular se logra fácilmente. Pero los asistentes no participan exclusivamente como espectadores, algunos desempeñan un rol activo. El epicentro del desfile es la estatua del prócer y el estrado donde se ubican las autoridades. Ante ellos desfilan Sociedades Criollas $^{26}$, militares y escolares. Las primeras desfilan a caballo representando a los "ancestros", al "linaje" de quienes dieron su vida por la patria junto a Artigas. Luego le siguen los regimientos militares que se consideran a sí mismos "hijos predilectos" de Artigas, encargados de una misión extraordinaria, la custodia de la nación. Por último, los escolares, las nuevas generaciones, el futuro. Todos juntos, desfilan en forma armónica, en un ritual de orden $^{27}$ reafirmando con su participación el éxito histórico del Estado-nación uruguayo en unir en el pasado a los uruguayos y asegurando la perpetuidad de esta cohesión en el presente y hacia el futuro. Año a año, durante décadas, esto era lo que se realizaba -y que tras el paréntesis del DNM se ha retomado- en cada 19 de junio.

\section{La mito-praxis ochentista}

Hice referencia a la preponderancia del Partido Colorado (PC) en la historia política nacional. El punto más alto de su extensa hegemonía ocurrió durante la primera mitad del siglo XX cuando una de sus fracciones -el batllismo- impulsó en el país una serie de reformas que configuraron lo más cercano a un Estado benefactor. Los logros alcanzados en cuanto a prosperidad económica, estabilidad política y avances sociales inéditos en

\footnotetext{
${ }^{26}$ Asociaciones de la sociedad civil que reivindican las tradiciones rurales del siglo XIX tales como vestirse de gaucho, tomar mate, comer asado o desfilar a caballo. Surgieron a inicios del siglo XX como modo de contrarrestar la inmigración masiva europea, la cual -con su mezcla de acentos y costumbres foráneas- se consideraba una amenaza para la joven nación uruguaya desde el nacionalismo esencialista.

27 Roberto da Matta, O que faz o Brasil, Brasil?, Rocco, Rio de Janeiro, 1989.
} 
relación a su trayectoria previa y a sus pares del subcontinente se trasladaron al imaginario colectivo. Expresiones como la "Suiza de América" o el "país modelo" se hicieron corrientes generando un culto a la "excepcionalidad uruguaya". La evidencia más palpable de esta fe era la integración social ascendente que posibilitó la apuesta del batllismo. Pero su proyecto mostró pronto sus limitaciones para un pequeño país dependiente, lo que trajo aparejado estancamiento económico, crisis social y finalmente, política, desde los sesenta hasta el fin de la dictadura. Esta nueva realidad erosionó el mito del "país modelo" durante aquellos años. Sin embargo, al comenzar la transición se apeló a dicho credo para sustentar el retorno a la institucionalidad democrática.

Si el nacionalismo esencialista postula la existencia de la nación en la gesta independentista y en el héroe que la engendró, para el discurso "ochentista" el Uruguay es una nación porque es una nación democrática. El valor por excelencia que hace "única" a la nación uruguaya es -en sus propias palabras- el "espíritu de tolerancia" de la democracia. Durante la primera mitad del siglo XX la democracia también era un elemento de elaboración de la identidad -y de orgullo- nacional, pero no era el único. Convivía con otros como la educación pública, la alta cultura, el perfil cosmopolita europeizante montevideano entre otros. ${ }^{28}$ En los ochenta era el elemento primordial. En esta narrativa la democracia no es sólo un régimen político, un mero procedimiento para regular la elección y funcionamiento de un gobierno, sino una fuerza espiritual superior que rige el "destino" nacional. A esto le llamo "esencialismo democrático". ${ }^{29}$ En el apartado anterior expuse como este discurso constituyó la argamasa ideológica que cimentó la política estatal de "pacificación nacional" de la transición. Pero fue algo más que un discurso ideológico coyuntural. Por eso lo defino como un credo. Como fue dicho, el pasado reciente -con su asimetría interna señalada- era la gran herejía a expurgar de la historia nacional, para no "manchar" el pasado verdaderamente representativo de la "uruguayidad". De ahí la necesidad imperiosa de su olvido.

En cuanto a su ritualidad, la actualización práctica del mito en la coyuntura ${ }^{30}$, los ritos afirmativos de este credo cumplen el papel -sobre todo durante la transición- de exorcizar el mal y reconciliar a la comunidad de feligreses con sus principios axiales. El primer lugar de importancia lo ocupan las elecciones. Pueden ser subdivididas en diversas secuencias, desde lo más colectivo -los grandes mitines masivos- a lo más individual -la entrada al "cuarto secreto"-. Una secuencia clímax de esta tradición consiste en un estrecho abrazo entre los candidatos presidenciales al confirmarse los resultados del comicio. El candidato perdedor concurre hasta la sede partidaria a felicitar al nuevo presidente electo y ambos se estrechan en un apretado abrazo. Esta secuencia se originó en las elecciones de 1984 cuando Alberto Zumarán, candidato del PN, concurrió a saludar a Sanguinetti. El gesto se repitió en otras elecciones. Lo que exhibe el rito democrático del abrazo es que el oponente político es un adversario ocasional, no un enemigo a eliminar, como en los

\footnotetext{
${ }^{28}$ Carina Perelli y Juan Rial, De mitos y memorias políticas, Montevideo, 1986.

${ }^{29}$ Alvaro de Giorgi, “¿Después de la violencia? Una reflexión sobre el caso uruguayo”, en José López Mazz, Elizabeth Anstett y Denis Merklen (eds), Editorial Banda Oriental, Montevideo, 2016, pp 33-44.

${ }^{30}$ Lo que Marshall Shalins denomina mito-praxis en Islas de Historia. La muerte del capitán Cook. Metáfora, antropología e historia, Gedisa, Barcelona, 1997.
} 
regímenes totalitarios. El referéndum -una elección directa- es otro rito central. Vaya si jugó un papel clave en la transición uruguaya. El acto de asunción de los nuevos gobernantes, en particular, el ritual de asunción presidencial, que en Uruguay sucede en cada $1^{\circ}$ de marzo, es otro ejemplo.

\title{
Otros credos: la gran familia indivisa y la reconciliación cristiana
}

\begin{abstract}
asumir ante él [ el Padre de la Patria ] y ante todos los uruguayos los que ya pasaron, los que estamos y los que vendrán, que nunca más en nuestro país se levantará un hermano contra un hermano $\mathbf{3 1}$
\end{abstract}

La "reconciliación nacional" y "nunca más un hermano contra otro hermano", son dos expresiones centrales del discurso vazquista respecto al "Nunca Más". Su preponderancia evidencia los trazos de dos creencias constitutivas de la cultura occidental: la familia como base de la sociedad y la religión cristiana. Pero la cuestión nacional no deja de estar presente puesto que la familia se invoca metafóricamente al representarse a la nación como una gran familia. Pero no una noción plural de familia, sino el modelo "tradicional" de familia, patriarcal y nuclear, ampliamente extendido como ideal en todas las clases sociales de nuestros países bajo la influencia del catolicismo en el pasado y continuado por los medios de comunicación y la publicidad en la actualidad. Se trata de las representaciones que conciben a la familia como espacio de unión incondicional entre sus miembros, en el que todos se aman y ayudan desinteresadamente, donde impera la armonía y el consenso y los conflictos quedan de lado, donde se halla amparo y protección frente a las adversidades del mundo exterior, donde se transmiten los valores primordiales de la sociedad a la nueva generación. ${ }^{32}$

La representación de la nación a través de esta metáfora no es nada original en la vida política. Tampoco su aplicación como recurso para procesar pasados conflictivos. ${ }^{33}$ Mencionaré dos ejemplos internacionales. El primer caso remite al perfil discursivo adoptado por organizaciones de familiares de víctimas de la violencia guerrillera en Argentina. Para obtener visibilidad en la esfera pública estos actores apelaron a la representación del pasado reciente como una desgraciada "guerra fratricida"

\footnotetext{
El recurso utilizado para lograr su reconocimiento es la nacionalización e igualación de los "muertos de una guerra fratricida". Para eso, es necesario que tanto el período de violencia política como la represión ilegal estatal sean interpretadas como un amplio entramado de lazos fraternos que incorpora a la Nación en su totalidad como víctima. (...) La Memoria Completa apela al lenguaje del parentesco y de la filiación con que el discurso patriótico denota los vínculos que unen a todos los connacionales con su patria. Al igual que la imagen primaria de la familia, la patria representa el dominio del amor, de los vínculos
}

31 Tabaré Vázquez, conferencia de prensa en Edificio Libertad, 26.12. 2006.

32 Vania Salles y Rodolfo Tuirán, "Mitos y creencias sobre la vida familiar", Revista Mexicana de Sociología, 58-2, 1996, 117-144.

33 Véase al respecto el capítulo 5 de Elizabeth Jelin, La lucha por el pasado. Cómo construimos la memoria social. Siglo XXI, Buenos Aires, 2017. 
afectivos desinteresados que unen a padres con hijos, a hijos con padres y a hermanos entre sí. ${ }^{34}$

El otro ejemplo proviene de la transición española. En su notable estudio sobre la construcción de la memoria de la Guerra Civil durante la transición a la democracia, Paloma Aguilar cita la carátula de un libro sobre los escritores españoles durante la guerra, de Fernando Díaz-Plaja, publicado en 1979, como caso paradigmático de la noción ampliamente dominante de dicha contienda como una "gran locura colectiva" en el discurso político e intelectual de la época. Dicho texto comienza con una especie de "parábola de los dos hermanos" al describir las opciones políticas antagónicas de Antonio y Manuel Machado, adscriptos respectivamente a la República y el franquismo

mientras Antonio Machado dirigía unos versos a Líster, su hermano Manuel elogiaba al general Moscardó (...) Eran dos pruebas de la locura que había invadido a los españoles. A todos los españoles, incluso a los más eximios escritores. Sí, España entera perdió la cabeza. La pasión le pudo al sentido común, la razón perdió ante la insensatez, el hermano de ayer se convirtió en el enemigo de hoy; quien compartía mesa de café y aun mesa familiar se volvió un enemigo mortal al que había que matar para que el país fuese feliz ${ }^{35}$

Respecto a la otra gran tradición de la cultura judeocristiana occidental -por más que la secularización haya sido profunda en la sociedad uruguaya- igualmente ha dejado su huella. La noción de "reconciliación" es un componente central de dicho credo. La religión católica institucionalizó un sacramento con tal término, el sacramento de la penitencia y reconciliación: "Se le denomina sacramento de reconciliación porque otorga al pecador el amor de Dios que reconcilia: 'Dejaos reconciliar con Dios' (2 Co 5,20). El que vive del amor misericordioso de Dios está pronto a responder a la llamada del Señor: 'Ve primero a reconciliarte con tu hermano' (Mt 5,24)". ${ }^{36}$ En la interpretación del pasado reciente expuesta desde el discurso vazquista subyace también esta tradición al representarlo bajo la figura de "pecado fratricida". Vale recordar que para la Biblia todos los hombres son hermanos puesto que descienden de la misma pareja, y por ende, en cierto modo, todos los asesinatos -más allá del que Caín comete a Abel- son considerados fratricidios. El fratricidio es una forma de incumplimiento del quinto mandamiento del Decálogo que ordena: "no matarás".

\footnotetext{
34 Valentina Salvi, “ 'Todos somos víctimas'. Transformaciones en la narrativa de la 'reconciliación nacional' en la Argentina", en José Luis Lanata (comp.) Prácticas genocidas y violencia estatal en perspectiva transdiciplinar, Universidad Nacional de Río Negro, San Carlos de Bariloche, 2014, p. 159.

35 Paloma Aguilar, Memoria y olvido de la Guerra Civil española, Alianza Editorial, Madrid, 1996, p. 285. El libro de Fernando Diaz Plaja es "Si mi pluma valiera tu pistola”. Los escritores españoles en la guerra civil, Plaza \& Janés, Madrid, 1979.

${ }^{36}$ Catecismo de la Iglesia Católica. Los siete sacramentos de la Iglesia. http://www.vatican.va/ archive/catechism_sp/p2s2c2a4_sp.html
} 


\section{Rituales de reconciliación: los casos chileno y español}

Alicia del Campo propuso la categoría "ritual de reconciliación" para analizar la teatralización política desplegada durante el gobierno de Patricio Aylwin (1990-1994). Resalta como los pasados de la Unidad Popular y la dictadura fueron representados por el gobierno como una gran disrupción en la historia chilena: una "gran caída del paraíso, entendido como la tradición democrática chilena y la de una nación unida en una Gran Familia"37. La autora cita como ejemplos la forma en que se dio a conocer públicamente el Informe Retting -el "Nunca Más chileno"- por parte de Aylwin y los funerales de dos figuras emblemáticas de cada pasado "problemático": el de Allende por un lado y el de Jaime Guzmán -estrecho colaborador del régimen pinochetista, político de la UDI, asesinado por una organización armada de izquierda- por otro. Mi interés es reparar en estos antecedentes y conceptualización para comprender mejor el DNM vazquista. Aylwin hizo público el Informe el 4 de abril de 1991. Del Campo identifica al credo cristiano como el sustento central de la política de pacificación del gobierno al girar en torno a "las nociones clave de sacrificio y redención"

en el reconocimiento público televisivo del informe el presidente hace un llamado a la reconciliación nacional que se transformará en el elemento retórico clave que guiará todo el modelo explicativo que, desde el Estado, intenta anular la conflictividad de intereses aún presente y su potencial amenaza a la estabilidad de la transición. El argumento central de su discurso está en la capacidad de silenciar al victimario y hacer aparecer los abusos como un crimen para el cual solo hay víctimas. Dado que la simetría del perdón cristiano requiere la existencia de un arrepentido, el discurso de Alwyin construye a la nación como el gran victimario/culpable, por haber sido cómplice de estos actos con su silencio. En el marco de esta lógica toda la ciudadanía debe pedir perdón 38

Respecto a la apropiación ritual estatal de las dos figuras políticas mencionadas, es ampliamente sabido la importancia de los rituales funerarios en toda sociedad, significación que se acrecienta con la muerte de figuras políticas, y más aún si su deceso fue resultado de la violencia política. En el caso de Salvador Allende se trató de la exhumación de sus restos para efectuar una ceremonia de re-enterramiento como acto de reparación simbólica puesto que en 1973 había sido enterrado de apuro, en secreto y obviamente sin ningún tipo de reconocimiento oficial a su estatus político dadas las circunstancias de su muerte. Esto ocurrió diecisiete años después, el 4 de septiembre de 1990. Sin embargo, el sentido dominante de esta ceremonia al desenterrarlo fue procurar enterrar su pasado socialista al resignificar su legado como el de un gran demócrata, despojado de sus aristas conflictivas para el nuevo sentido común dominante: "al resignificarse a Allende como un gran

\footnotetext{
37 Alicia del Campo, Teatralidades de la memoria: rituales de reconciliación en el Chile de la transición, Santiago de Chile, Mosquito Comunicaciones, 2004, p. 85.

38 del Campo, op. cit., 93.
} 
demócrata se lo redime a él y a Chile del gran pecado: la caída del paraíso democrático y la división de la familia de hermanos que conforma la nación". ${ }^{39}$ Cronológicamente, primero se produjo esta ceremonia "reparatoria" de Allende, luego un semestre después ocurrió la presentación del Informe Retting lo que habilitó la emergencia del discurso crítico del terrorismo de Estado por parte de organismos de derechos humanos pero tal posibilidad se canceló rápidamente al producirse un mes después el asesinato de Guzmán. Obligado por las circunstancias, el gobierno debió participar del ritual fúnebre de esta figura devenida en el "cordero sacrificial de la reconciliación nacional" como lo llama del Campo. La muerte de Guzmán terminó siendo funcional como el complemento simétrico al "gesto sacrificial" de Allende escenificado unos meses antes. Sus muertes no fueron expuestas desde el discurso estatal como resultado de causas políticas, sino por obra de un mismo "desborde pasional" que las unificaba en su condición de resultantes de la "desviación antidemocrática". Ambos entierros -combinados en los hechos por su proximidad- terminaron adquiriendo un valor purificador para el re-encuentro de la nación con sus principios más sagrados -el "respeto a la vida y la convivencia tolerante democrática" desde el sentido que procuró impregnarles el Estado como principal productor ejecutivo.

Otro ejemplo internacional posee un estrecho aire de familia con el DNM; antecedente que remite nuevamente a España. Se trata de una ceremonia realizada en Madrid el 22 de noviembre de 1985, la cual puede conceptualizarse como un ritual de reconciliación de la Guerra Civil organizado por el rey Juan Carlos I. La fecha seleccionada no tenía directa relación con un acontecimiento ocurrido durante la guerra sino con la biografía política del productor ejecutivo: se cumplía ese día el décimo aniversario de su proclamación como monarca y jefe de Estado -y también el décimo aniversario de la muerte de Franco-. Su emplazamiento físico de realización tampoco tuvo que ver con un lugar asociado a la guerra pero sí a un espacio sacralizado del nacionalismo esencialista español: la Plaza de la Lealtad y el monumento ubicado en su centro denominado A los Héroes del Dos de Mayo. Ambos evocan la memoria martirológica de los fusilamientos de varios de los insurrectos contra la invasión napoleónica de 1808. Juan Carlos I resignificó este memorial ampliándolo, al cambiarlo de nombre por el de Monumento a los caídos por España definición tan laxa y genérica como la del "Nunca Más" vazquista. Todos los españoles muertos en conflictos de todas las épocas podían ser integrados a tal lema. Para la performance central del ritual el rey convocó a escena a los ex combatientes de regimientos republicanos y franquistas

había representantes de organizaciones de la República como la Asociación de Aviadores, la Fraternidad Democrática de Militares del Ejército de la República, o el cuerpo de Carabineros. Del lado franquista figuraban algunos integrantes de la agrupación Mutilados por la Patria. Miembros de uno y otro bando mostraban ayer su satisfacción por el acto de "reconciliación definitiva" que simbolizaba para ellos el monumento a los caídos. Numerosos madrileños presenciaron también una ceremonia

39 del Campo, op. cit., 229. 
marcada por la sobriedad y la emoción, que concluyó con un breve desfile militar 40

\section{Los "derechos humanos"}

La última creencia subyacente en el DNM es la narrativa ecuménica de los derechos humanos. Su impronta es muy marginal como se observará en el apartado siguiente. Pero se halla nada menos que en el nombre del acto. La tradición nacional y regional de este credo ${ }^{41}$ está estrechamente conectada a lo ocurrido en el pasado reciente y a las críticas a las políticas de olvido e impunidad del terrorismo de Estado. Por ello en estas latitudes referir a los "derechos humanos" es cuasi sinónimo de reclamar avances en materia de justicia transicional. Ha sido señalado por varios autores como luego de la derrota que significó las dictaduras, las izquierdas vernáculas reorientaron su fe desde la utopía revolucionaria hacia este otro credo de cuño liberal, producto del contacto de su militancia en el exilio con redes transnacionales de activistas estadounidenses y europeos. ${ }^{42}$ Resulta más útil de comprender esta tradición local-regional del "Nunca Más al terrorismo de Estado" si se consideran sus expresiones rituales antes que sólo como mito. Recurro nuevamente a ejemplos del exterior, en este caso, Argentina.

Dos modalidades básicas de dispositivos rituales creados para comunicar -y defender- el "Nunca Más al terrorismo de Estado" o "los derechos humanos"- se distinguen desde 1983 al presente en el vecino país: una, en momentos de expansión de la justicia transicional; otra, en momentos de retroceso. El Juicio a las Juntas celebrado entre abril a diciembre de 1985 es el más paradigmático ejemplo de la primera modalidad. Uno de los rituales políticos, sino el más célebre de todos los rituales de la justicia transicional de la época contemporánea a nivel global. ${ }^{43}$ Las conmemoraciones en repudio al golpe de Estado de cada 24 de marzo constituyen la forma paradigmática de lo segundo. El papel protagónico en cada caso le cupo a actores estatales -presidentes como Raúl Alfonsín y Néstor Kirchner o el fiscal Julio Strassera- y a la sociedad civil respectivamente -Madres y Abuelas de Plaza de Mayo, Hijos, etcétera-. La centralidad de los actores, el marco escenográfico, las secuencias que lo componen, son diferentes en cada modalidad básica pero el guión es casi el mismo: "nunca más crímenes de lesa humanidad", "nunca más terrorismo de Estado".

\footnotetext{
40 "El Rey inaugura el monumento a los caídos por España en presencia de ex combatientes de los dos bandos", El País [de Madrid], 23 de noviembre de 1985, citado en Aguilar, ob. cit., p. 284.

${ }^{41}$ Considerar esta narrativa como creencia o mito no debe interpretarse como una desacreditación de sus postulados, como un engaño opuesto a la "realidad". Jenna Reinbold desde la sociología de la religión aplica la noción de mito al estudio de la primera Declaración Universal de los Derechos Humanos de 1948 en Seeing the myth in Human Rights, University of Pennsylvania Press, Philadelphia, 2017.

${ }^{42}$ Para el caso uruguayo ver Vania Markarian, Idos y recien llegados, 1967-1984. La izquierda uruguaya en el exilio y las redes transnacionales de derechos humanos, Ed. De la Vasija/CEIU, México, 2006.

${ }^{43}$ Véase al respecto Kathryn Sikkink, "From pariah State to global protagonist: Argentina and the struggle for International Human Rights", Latin American politics and society 1, 2008, p. 1-29.
} 
Respecto a esta tradición en Uruguay vale recordar que hubo un libro "Nunca Más" uruguayo -su título específico fue "Uruguay nunca más: informe sobre la violación a los derechos humanos (1972-1985)"- de 1989, pero publicado desde la sociedad civil. La consigna "Nunca Más", desde que cruzó el río de la Plata en 1984 fue apropiada inmediatamente por el movimiento local de derechos humanos y sus aliados. Si los 24 de marzo son la expresión ritual del "Nunca Más al terrorismo de Estado" argentino, en Uruguay su símil es la "Marcha del Silencio". Organizada por Madres y Familiares de Uruguayos Detenidos y Desaparecidos, se realiza -desde el año 1996- bajo ese nombre, cada 20 de mayo, por 18 de Julio, la principal avenida de Montevideo -y posteriormente, en muchas otras ciudades- en demanda de "verdad y justicia". Su estrategia performática central es marchar en silencio portando únicamente fotografías de los desaparecidos, sin distintivos partidarios o de otra naturaleza. Debido a este antecedente ritual es que cuando se desarrollaron los debates en la esfera pública al presentarse la iniciativa del DNM, desde actores sociales y políticos de la izquierda se sostuvo: "pero sí ya tenemos un 'Día del Nunca Más': la Marcha del Silencio". ${ }^{4}$

\section{En la escena}

El DNM se implementó en cuatro ediciones, tres (2007 a 2009) durante el gobierno de Vázquez y la cuarta (2010) durante el primer año del gobierno de José Mujica. A partir de 2011 se volvió a conmemorar la fecha exclusivamente como el "Natalicio" en Sauce. Su puesta en escena se estructura en dos secuencias básicas: a) apertura con colocación de ofrenda floral a Artigas por parte del presidente; b) desfile cívico-militar por avenida 18 de Julio con epicentro en Plaza Independencia.

\section{Apertura: redención y abrazo fraternal}

La apertura del ritual -única secuencia que se repite a lo largo de sus cuatro ediciones- no es original del DNM, proviene del "Natalicio" y de un sinnúmero de ceremonias semejantes. De las cuatro ediciones implementadas la más significativa fue la primera. A su vez, fue donde la secuencia de apertura cobró mayor intensidad dramática. Debido a ello me concentraré en lo ocurrido el 19 de junio de 2007. La polémica previa que se mantuvo hasta horas antes de su realización fue determinante para la preponderancia de esta primera secuencia al modificar Vázquez su plan inicial. ${ }^{45}$

\footnotetext{
${ }^{44} \mathrm{Al}$ respecto del libro referido y la Marcha del Silencio ver Marchesi y Winn, ob, cit., p.161 y 147.

45 “A raíz de la polémica surgida, Vázquez consideró que 'no estaban dadas las condiciones adecuadas para realizar grandes conmemoraciones ni grandes desfiles (...) todavía hay rispideces y desencuentros en el seno de la sociedad uruguaya, por lo cual sería irresponsable convocar a un gran acto conmemorativo para seguir ahondando el camino del Nunca más y el reencuentro entre los uruguayos. Espontáneamente, quien quiera acompañarnos, acompañe, y quien no quiera hacerlo, tiene toda su libertad para no hacerlo'. Vázquez dijo que simplemente colocará una ofrenda floral en el pie del monumento a Artigas y que no hará uso de la palabra", "Civiles, militares y policías convocados por el presidente Vázquez proclaman el Nunca Más", La República, 19 de junio de $2007,2$.
} 
El presidente arribó a las once horas a la plaza Independencia en su automóvil oficial. Junto con su esposa se detuvo a saludar a Lilí Lerena, viuda de Líber Seregni, líder histórico del FA fallecido meses antes de obtener el gobierno. Ambas portaban claveles blancos en la mano. Dio unos pocos pasos más y saludó a Nicolás Cotugno, arzobispo de Montevideo, la máxima autoridad eclesiástica nacional, notorio conservador. Búsqueda reproduce el diálogo que mantuvieron: 'Presidente, venimos a acompañarlo y a manifestarle nuestro deseo de que haya reconciliación y paz entre todos los orientales' le dijo Cotugno, 'Monseñor, rece por mí' le contestó el mandatario." ${ }^{6}$ Luego siguió solo, caminando lentamente, con movimientos pausados, como en una procesión, subiendo cada escalón hasta colocar la ofrenda. El protocolo indica que debe ser acompañado por el Ministro de Defensa y el edecán militar -así ocurrió en ediciones posteriores-. Sin embargo, esa vez el presidente efectuó ese acto en solitario. La ofrenda consiste en un pabellón nacional confeccionado con flores transportada por dos Blandengues -pero éstos son parte de la escenografía, no están investidos de condición humana-. "El presidente permaneció unos minutos frente al prócer en actitud reflexiva" dice el audio de Subrayado. ${ }^{47}$ Más que reflexiva, fue reverencial según puede observarse en el conjunto de fuentes fotográficas y audiovisuales disponibles. La secuencia implicó poner en acción un elaborado conjunto de significantes: el manejo del tiempo, del espacio escenográfico, la gestualidad corporal -la intensidad de la mirada, la inclinación de la cabeza-, la austeridad de otros elementos auxiliares y, sobre todo, el silencio.

Si la política puede ser metaforizada como un teatro, es claro que en esta puesta en escena el productor ejecutivo de la obra es a su vez el actor protagónico. Esta primera -y única gran secuencia en esta edición- parecería ser un unipersonal puesto que habría un único personaje en la escena. No obstante, son dos los actores protagónicos: el presidente y Artigas. Lo que transmite esta secuencia es el encuentro entre ambos. La gestualidad desplegada por Vázquez expresa el carácter especial de este encuentro: se trata de una comunión extraordinaria. La ubicación diferencial del presidente por encima del resto del cuerpo social, incluso de su cortejo más próximo, tanto familiar como institucional, simboliza su cualidad para comunicarse con el "padre de la Patria". Esta comunión espiritual no requiere del uso del habla común de la gente corriente. Ello contrasta con lo sucedido en los días, los meses, los años y las décadas previas. Con la incomprensión que obtuvo su iniciativa y con el "palabrerío" que inundó al tema en los últimos meses, con la desidia de los gobiernos democráticos previos que no supieron resolver antes el problema, con el crimen fratricida practicado en los años trágicos. Todo ello queda atrás con el gesto del Gran Encuentro. La primera reconciliación es entre el Presidente (que representa a todos los uruguayos) y el Progenitor de todos los uruguayos.

\footnotetext{
46 “Ante poca militancia de izquierda, pero con integrantes del gobierno, oposición y militares, Vázquez realizó su acto del 'Nunca Más”, Búsqueda, 21 de junio de 2007, 4.

47 www.subrayado.com.uy/noticias/24554/el-dia-del-nunca-mas-que-quedo-para-el-olvido. Además de fuentes de prensa escrita, los montajes del evento se pueden analizar a partir de fuentes audiovisuales existentes en internet producidas por informativos de la televisión privada (como Subrayado) y el propio registro oficial de Presidencia de la República que posee un archivo propio en línea.
} 
La acción comporta además un componente sacrificial, redentor. El presidente está allí de esa manera porque otros no están: quienes cometieron el pecado fratricida en el pasado; aquellos que no comprendieron el sentido profundo de la convocatoria en el presente. Pese a ello, la reconciliación debe seguir, el presidente debe hacerla, solo, si es necesario. El gesto se inscribe y emula al propio Artigas en una de las más recordadas frases del esencialismo nacionalista: "cuando me falten hombres para combatir a sus secuaces, pelearé con perros cimarrones" le habría respondido Artigas a Lecor, comandante del ejército portugués, cuando éste le conminó a rendirse.

En el día del nacimiento del Dios-padre, día del nacimiento de la Patria, el Presidente -su representante en la tierra- es el encargado de reanimarlos colocándole la ofrenda floral como símbolo de renovación de la vida. Si Artigas es la deidad suprema de la religión civil uruguaya, su estatua es adscribible a un altar y el presidente a un sumo sacerdote. La ofrenda es la expresión material de la adoración a esta entidad superior. Puede significar veneración, gratitud, reconocimiento; también una súplica. Esos minutos de "extremo recogimiento" en que, solo, en silencio, separado del resto de los asistentes, Vázquez mira fijamente a Artigas, se asemejan mucho a una plegaria. Su gestualidad se enmarca claramente en la liturgia cristiana del pedido de perdón por los pecados cometidos y de la súplica por la liberación definitiva del mal. ${ }^{48}$ Culminados esos minutos, el presidente desciende lentamente del altar de la Patria. Una voz lejana desde el público tras las vallas rompe el silencio: "¡Vamos Tabaré!”.

Eso era hasta ahí el acto programado. Pero la acción se prolongó con un aditivo no planificado. Sobre la avenida 18 de Julio en la primera fila del cortejo que aguardaba el descenso del presidente lo esperaban los dirigentes partidarios de la oposición Jorge Larrañaga del PN, Pedro Bordaberry del PC, Pablo Mieres del Partido Independiente $^{49}$.Vázquez se fundió en un estrecho abrazo con cada uno. El que más impacto público tuvo fue el efectuado con Pedro Bordaberry, por ser éste el hijo del exdictador procesado unos meses antes. El Observador le dedicó la foto de portada, Búsqueda, una vez más reprodujo sus diálogos: "Quizás la imagen más representativa del acto fue el abrazo que se dieron y las breves expresiones que intercambiaron Vázquez y Pedro Bordaberry. 'Gracias por venir' dijo el presidente. 'Gracias por hacer esto' le respondió el precandidato presidencial colorado" $" 50$.

Lo que estos actores políticos representaron en el primer plano de la escena fue el rito del abrazo del esencialismo democrático antes mencionado. Recuérdese que simboliza la tolerancia, el respeto, la convivencia pacífica como valores inherentes de la

\footnotetext{
48 Como fue visto un antecedente a nivel internacional de este gesto es el de Aylwin pidiendo perdón en nombre de toda la sociedad en la presentación televisiva del Informe Retting. El paralelismo con la performance del Día de la Expiación -o día del Perdón- de la tradición judeocristiana son evidentes. El modo en que el sumo sacerdote ingresaba al templo como mediador entre Dios y el pueblo, tal como lo describe la obra clásica de Hubert y Mauss sobre el sacrificio: Henri Hubert y Marcel Mauss, "De la naturaleza y de la función del sacrificio", en Marcel Mauss, Lo sagrado y lo profano, Obras I, Barral, Barcelona, 1970.

${ }^{49}$ Los dos primeros, de ambos partidos tradicionales, aspirantes a renovar los viejos liderazgos de los expresidentes Sanguinetti, Batlle (PC) y Lacalle (PN), quienes cómo se afirmó, se opusieron tajantemente a la iniciativa y en consecuencia no concurrieron.

${ }^{50}$ Daniel Gianelli, “El acto de la Plaza”, Búsqueda, 21 de junio de 2007, 4.
} 
"uruguayidad". Son muy pocas las instancias en que se reproduce este acto fuera de la noche de cierre electoral. Por lo general los líderes opositores partidarios y el presidente polemizan a través de los medios masivos; raramente se abrazan tan enfáticamente en la escena pública. El presidente y estas figuras políticas se mostraron como hermanos profundamente fraternos y no como hermanos fratricidas. ${ }^{51}$

La pretensión inicial de Vázquez en su convocatoria era que la iniciativa fuera acompañada por un amplio espectro de actores sociales y políticos, pero por sobre todo que se hicieran corporalmente presentes en el acto -la forma por excelencia de demostrar adhesión en un ritual- aquellos sectores $\mathrm{u}$ organizaciones sociales que de algún modo "representaban" las partes más implicadas en el conflicto interno del pasado reciente, tales como las asociaciones de víctimas de la represión dictatorial y las asociaciones de retirados militares. Que se hicieran corporalmente presentes -y conjuntamente- "representantes" de los "polos extremos", aquellas partes del todo social que llegaron a cometer el pecado fraticida $^{52}$ y/o -al menos- sus víctimas. Cabe aclarar que no disponía nada semejante al ejemplo español referido -ex-combatientes de "ambos bandos"-. En la medida en que este tipo de actores no concurrieron, no acompañaron la propuesta, el libreto se mantuvo, pero a último momento cambiaron los protagonistas y se readecuó la obra. Se concentró en el primer acto -que pasó a ser un unipersonal- y se suprimió el segundo -el desfile- ante la ausencia de voluntarios para hacerlo y se le sumó a último momento casi que espontáneamente un anexo al primero, que elevó al primer plano a otros actores que en principio no figuraban inicialmente en la marquesina. El presidente como redentor y las cúpulas político-partidarias dirigenciales como símbolo de confraternidad y tolerancia democrática, terminaron configurando el significado primordial del primer DNM.

\section{Acto segundo: "New York, New York"}

Las dos ediciones siguientes se iniciaron con la primera secuencia, pero ésta no tuvo tanto despliegue escénico. Fue mucho más contenida. El presidente colocó la ofrenda acompañado del ministro de Defensa y edecán militar y fue mucho más breve, cuasi protocolar. En 2008 encabezó el DNM Rodolfo Nin Novoa, vicepresidente en ejercicio de la presidencia por hallarse Vázquez en el exterior. En este año y el siguiente -en el que volvió a estar Vázquez- sí hubo desfile, por lo cual se asemejó al ideal planteado por el presidente originalmente. Por más que fuera menos solemne, y en cierto modo, desplazada

\footnotetext{
51 El más significativo en esta clave fue el abrazo Vázquez-Bordaberry. No solo representaban las condiciones de presidente y líder opositor democrático, sino a su vez a los hermanos enfrentados del pasado. Bordaberry a la dictadura -por ser hijo del dictador-, Vázquez a la izquierda. Los que más se enfrentaron en el pasado, deponen sus diferencias y se reconocen fraternalmente en la convocatoria y entrelazamiento de sus cuerpos. Lo más cercano a los "dos demonios" fundidos en un abrazo público que haya existido en toda la post-dictadura.

${ }^{52}$ En la edición 2008 circuló en los días previos en la prensa una versión que el presidente Vázquez habría realizado gestiones para que en el marco del DNM dirigentes tupamaros y militares pidieran mutuamente perdón. Pero ello no prosperó. Una constante de los DNM es al finalizar el acto la consulta de periodistas a dirigentes frenteamplistas con pasado tupamaro y a los altos mandos militares sobre sus respectivas responsabilidades en los hechos del pasado con el fin de obtener una declaración de arrepentimiento y/o pedido de perdón.
} 
por el desfile, la secuencia de apertura mantuvo su importancia al significar lo ya descrito: la escenificación del pedido de perdón al padre celestial por el pecado fratricida al mismo tiempo que la imploración de su ayuda para reafirmar el compromiso de que esos hechos nunca más se repitieran entre sus hijos-hermanos. El gesto del abrazo también se hizo presente pero se trasladó al final del acto, culminado el desfile, y tuvo mucho menos carga simbólica emocional que en la edición 2007..$^{53}$

La secuencia del desfile se desarrolló en una ubicación levemente desplazada del altar laico mencionado donde transcurre la apertura. No hay prácticamente intervalos entre una y otra secuencia, demora el tiempo que lleva desplazarse a pie de un lado a otro. El uso del espacio y circulación de los actores se configura en torno a un estrado techado, especialmente montado, de unos quince metros de largo. A su frente está adornado con cinco escudos equidistantes entre sí y de igual tamaño (unos sesenta $\mathrm{cm}$ de diámetro). En el centro, el Escudo Nacional. A sus flancos los escudos de la Policía Nacional y de la Armada hacia la derecha, el del Ejército y Fuerza Aérea a su izquierda, colocados en una continuidad que simboliza su unidad indisoluble y el resguardo que otorgan los ubicados hacia los costados respecto del que ocupa el centro. En la calle, en cada vértice del estrado dos Blandengues de pie, incólumes, sostienen respectivamente los pabellones Nacional y de Artigas. A unos pasos de ambos, dos personas de traje negro y corbata, de pie sobre la calle, ofician de custodios. El estrado posee un metro de altura, no más, por lo que si bien establece una demarcación entre lo alto y lo bajo, no es pronunciada. En lo alto, en el palco se ubican las autoridades. Abajo, quienes desfilan y el público general, como espectadores. Hay dos clases de espectadores del desfile, los ciudadanos comunes, el público anónimo e indiferenciado y las autoridades localizadas en el palco. ${ }^{54}$ Pero éstas tienen una doble condición son espectadores del desfile pero también son actores protagónicos del mismo. No desfilan, pero interactúan con los desfilantes, supervisan las acciones que realizan quienes desfilan. Hay muchos modos gestuales de realizar esta supervisión, siempre aprobatoria: sonrisas, aplausos, comentarios entre sí, o atento respeto en los pasajes más "solemnes". Un caso paradigmático de esto último es cuando quien comanda una formación militar se separa de la misma y realiza una reverencia hacia sus superiores -que incluye al presidente de la República- ubicados en el palco. No obstante, esto es, con mayor o menor gradación, generalizado para todos los desfilantes. Todos realizan alguna destreza especial al pasar frente al palco y quienes están allí celebran esa acción. La composición y ubicación dentro del palco de los actos oficiales está reglamentada formalmente por un Manual de Ceremonial del Estado y Diplomático. El presidente de la República ocupa el centro, a su derecha el vicepresidente, luego el ministro de Defensa Nacional, los Comandantes en Jefe de las tres armas y el Director Nacional de Policía. A la izquierda, el presidente de la Suprema Corte de Justicia, ministro del Interior y sigue un orden de precedencias hacia los extremos de la primera fila y la segunda fila con el resto del Poder

\footnotetext{
${ }^{53}$ En la edición 2009 el ritual coincidió con el año electoral. Por esa fecha -junio-, con las internas de cada partido para seleccionar su candidato presidencial. Los líderes opositores no concurrieron. Sólo fue el candidato oficialista, José Mujica, quien al finalizar el desfile se abrazó con el presidente Vázquez. Para 2010 -el último año de su escenificación - volvieron los abrazos interpartidarios.

${ }^{54}$ A lo que hay que agregarle los espectadores a distancia puesto que los canales privados de televisión abierta transmitieron en vivo el acto, lo que no ocurre generalmente con las demás "fiestas patrias".
} 
Ejecutivo, los presidentes de las cámaras de Senadores y Diputados, otros legisladores. En pocas palabras, el estrado ilustra y concentra la representación del poder institucionalizado del Estado. ${ }^{55}$ El desfile se inicia con el Himno Nacional una vez que todas las autoridades están ubicadas en sus respectivos lugares. El presidente da inicio formal al desfile.

En su guión original la obra DNM preveía dos actos: I - el mediador intercede ante el prócer y da inicio a la reconciliación; II - los hermanos antes enfrentados se reconcilian desfilando ante el prócer (estatua) y el mediador (estrado). En 2007 el acto II fue suprimido, pero en definitiva sustituido por el rito del abrazo del esencialismo democrático. En 2008 y 2009 se volvió a plantear la ausencia de los principales actores requeridos para la segunda secuencia. La producción ejecutiva definió esta vez que sí habría desfile, pero los políticos no iban a suplir este vacío.

Había ciertas incongruencias en el planteo de esta segunda secuencia. Vázquez manejó desde un principio la existencia de un desfile como un componente central de su proyecto del DNM. Los militares serían parte del desfile puesto que es su modo de participar en los actos patrios. Tampoco es una opción, en tanto institución integrante del Estado y subordinada al presidente de la República, es una obligación funcional. Dentro de los convocados al desfile se aludió también a escolares, liceales e incluso estudiantes universitarios. Sobre todo, los escolares son elementos cardinales de los desfiles patrióticos, no así los últimos. Además, éstos cuentan con su propia organización gremial autónoma del gobierno. Los escolares tampoco tienen mucho margen de decisión al respecto, pero los estudiantes universitarios sí. Y su tradición de expresión pública transita por otros carriles. Cuando intervienen en el espacio de la calle y la ciudad como las grandes escenografías de la política moderna, antes que desfilar, marchan. Este es el caso también de las otras organizaciones de la sociedad civil invitadas por el presidente a participar del DNM como los colectivos de defensa de derechos humanos o el PIT-CNT. Cuando ocupan la calle, marchan. Y el lenguaje dominante de la marcha es la protesta, la conflictividad; no así el del desfile que despliega la celebración del orden vigente y la cohesión de la sociedad. ${ }^{56}$ Otra opción era que este tipo de organizaciones asistieran al acto pero no desfilaran. Luego de la intervención aclaratoria de Vázquez sobre los alcances del DNM el 4 de junio del 2007 desde Presidencia de la República se llamó expresamente a Madres y Familiares de Detenidos Desaparecidos para consultar si iban a concurrir, lo que fue contestado negativamente para ese año y en cada edición siguiente. Entonces, si no comparecen y desfilan los desfilantes ideales, ¿quiénes fueron los desfilantes sustitutos -en lo que respecta a la parte civil del desfile- en 2008 y 2009 ?

\footnotetext{
55 En 2009 se montó un segundo palco en el que se ubicaron invitados especiales tales como integrantes del cuerpo diplomático y figuras de la farándula política local como Graciela Rompani de Pacheco, viuda del expresidente Jorge Pacheco Areco y Oscar Magurno, estrechamente asociados a la derecha colorada.

${ }^{56}$ En su primera edición, en junio de 2007, colectivos sociales de la denominada "izquierda radical" tales como Plenaria Memoria y Justicia y Fogoneros y un sector político del FA -Corriente izquierda-, que a los pocos años se iría del mismo, convocaron a un acto paralelo ese 19 de junio en repudio al DNM y en reclamo de "Nunca Más terrorismo de Estado". Las organizaciones sociales que impulsan la Marcha del Silencio no adhirieron a este acto paralelo que terminó con incidentes siendo reprimido por la policía.
} 
La parte civil del desfile estuvo a cargo de la banda de niños de Canelones, la banda estudiantil de Colonia, la banda juvenil de Rosario y la Asociación Patriótica del Uruguay. Luego, desfilaron las cuatro escuelas de formación de oficiales militares y policiales, acompañados por las respectivas bandas de músicos, y el Liceo Militar General Artigas, en todos los casos acompañados por sus pabellones y por último el Regimiento "Blandengues de Artigas" del Ejército. ${ }^{57}$

Hubo un desfile de bandas juveniles de varios departamentos y de las escuelas de formación militar y policial, más los Blandengues de Artigas. Durante el desfile, las bandas aportaron algunos hechos singulares. Por ejemplo, la banda juvenil de Florida marchó al son de la canción New York, New York, que fue acompañada con movimientos de cuerpo por varios miembros del cuerpo diplomático. Otro fue cuando la banda de la Escuela Nacional de Policía desfiló interpretando el tema central de la serie televisiva estadounidense SWAT, que relata las vivencias de una unidad táctica que se puede asimilar aquí al Grupo GEO. Los efectivos de las escuelas militares cantaron los himnos de sus respectivos centros educativos. ${ }^{58}$

A partir de las fuentes audiovisuales señaladas se puede observar con mayor precisión esta sección del DNM, puesto que la prensa escrita le presta escasa atención. ${ }^{59}$ Las agrupaciones civiles -la "parte civil" de acuerdo a la categorización de El Paísinauguró el desfile. Luego le sucedió la sección militar. En ambas ediciones, el cierre lo protagonizaron los Blandengues a caballo. Estas asociaciones civiles son bandas musicales juveniles del interior del país, de ciudades pequeñas, conformadas originalmente a partir de instituciones educativas aunque sin dependencia formal de las mismas, que cumplen un rol de integración social y entretenimiento en localidades donde hay escasas actividades de esparcimiento para adolescentes. Participan de eventos festivos o competencias con pares en desfiles, en localidades con ese perfil. Desfilar en Montevideo es todo un logro para ellas. Se componen de una parte musical y coreográfica, por lo general, dividida en términos de género. Los chicos se ocupan de la música, las chicas del baile. Aunque se observa un caso integrado por niños, el resto son adolescentes. En el desfile exhiben el dominio de destrezas musicales y coreográficas aprendidas en su proceso de socialización, demostrando así su capacidad de integración al nosotros mayor. Lejos de la contestación y "rebeldía" asociados a movimientos contraculturales de subculturas juveniles propios a esa edad en otros contextos socioculturales, su performance pública transmite armonía, contento, hasta obediencia. Las composiciones musicales que interpretan son hits pop de la industria cultural internacional como "New York, New York", originaria de una película de Holywood, luego popularizada por Frank Sinatra. Las coreografías no comportan ningún tipo de riesgo estético: cadencias suavemente bamboleantes, deslizándose en zigzags y

\footnotetext{
57 “Al son de la cubana Celia Cruz se cerró acto por el 'Nunca Más"”, El País, 20 de junio de 2008, 7.

58 "Un acto signado por el protocolo y el color de las bandas juveniles”, El País, 20 de junio de $2009,8$.

59 http://archivo.presidencia.gub.uy/_web/video/2008/06/nunca_mas_plaza_independencia.wmv http://archivo.presidencia.gub.uy/_web/video/2009/06/vid_190609_acto_19_junio.wmv
} 
saltitos cortos de las chicas mientras los varones llevan el ritmo de la percusión. El vestuario es más "osado" que la opacidad de las túnicas en los desfiles escolares ${ }^{60}$, con un tinte levemente sexuado de polleras cortas, colores vivaces y atuendos que remedan uniformes al estilo de las paquitas de Xuxa. Esta dramatización narrada por el pasaje de las bandas juveniles -la sección civil del desfile-, frente al palco no tiene nada de conflictiva, es pura "armonía".

Luego de las gráciles cadencias, el paso firme, aunque no tanto. En muchos Estados, sobre todo en las grandes potencias, cuando desfilan los militares en las "fechas patrias" exhiben una demostración de su poderío además de su lealtad hacia las autoridades. En las grandes potencias constituye un mensaje prioritariamente externo comunicado mediante el despliegue de la materialidad concreta del potencial guerrero: tanques y otros vehículos, aviones, armas, unidades especializadas. Sin embargo, dada la historia reciente del Uruguay, este cariz de los desfiles militares remite a su función represiva interna, lo que ha redundado en que, desde el retorno a la democracia en 1985, este tipo de performances han sido prácticamente desterradas en la sección militar de los desfiles patrios. Su lugar lo suplen las divisiones y regimientos que transmiten otras artes más tenues en su significación beligerante con la música como gran estandarte con los ritmos de las marchas, profusión de instrumentos altisonantes de viento y percusión, acompañada de coloridos uniformes, distintivos, enseñas y coreografías de pasos enérgicos, combinados. O sea, no desfilan los Coraceros. Participan la versión más edulcorada posible de las Fuerzas Armadas. Ante la invocación superior del presidente traigo una canción y no la guerra.

Además de la dimensión musical-festiva hay otro dato que comparten las secciones civil y militar del desfile. Son en su inmensa mayoría, adolescentes y jóvenes los desfilantes. En el caso de los militares, son fundamentalmente los cadetes de las escuelas de policía y de las tres armas militares -con sus respectivas bandas musicales - los grupos que desfilan. En síntesis, el desfile sustitutivo está compuesto por las nuevas generaciones de civiles y militares juntos que, en vigoroso movimiento, demuestran su compromiso patriótico. Estos buenos hijos-hermanos de la Patria y de Artigas representan lo opuesto a la

\footnotetext{
${ }^{60}$ La preocupación en los medios por remarcar qué actores políticos y sociales asistían y quienes no al DNM fue una constante de cada montaje. Sin embargo, no llamó la atención de igual manera una ausencia significativa del desfile: la escuela pública. Esta ausencia no fue total puesto que en el registro audiovisual de 2009 pueden constatarse niños de una escuela pública desfilando. Pero fue la excepción a la regla. La escuela pública está en el ADN de los rituales patrióticos. En cada acto oficial, en el "Natalicio" notoriamente, es impensable que no desfilen las escuelas públicas. Esto es así puesto que, para el esencialismo nacionalista, todos los miembros de la nación son hijos de la patria, pero lo son por sobre todo quienes han pasado por la escuela pública. La escuela es la madre colectiva más terrenal de la patria. Los hijos del Uruguay son resultado de la unión del Dios-padre Artigas con la gran madre Escuela-maestra. Esta ausencia se explica porque ADEMU, el gremio de maestros de enseñanza primaria se pronunció explícitamente en 2007 en contra de participar del DNM por la ambigüedad de éste en el rechazo al terrorismo de Estado. Significativamente, las trazas del credo del "Nunca Más terrorismo de Estado" se manifestaron en los montajes del DNM solamente mediante ausencias: cuerpos que no están, símbolos fuertes del imaginario nacional que no están.
} 
generación que se encarnizó en "matarse mutuamente". Son los buenos hermanos fraternos; son el promisorio futuro y la negación del pasado. ${ }^{61}$

¿Qué se puede afirmar respeto al público general? "Los rituales constituyen posicionamientos culturales estratégicos por medio de códigos dramáticos, orientados a una puesta en escena de la identidad nacional. Cada ritual ejerce una oferta de un cierto libreto/trama dentro del cual yo como ciudadano(a) me identifico, me posiciono y establezco alianzas con unos u otros personajes de la trama". ${ }^{2}$ "Presente mi General, presente mi Presidente" decía un cartel colocado al lado de la ofrenda al pie de la estatua por una persona anónima que quiso demostrar de este modo tan enfático su identificación con la trama. Algunos asistentes vitorearon al presidente, y unos pocos se aproximaban a saludarlo. En lo que respecta al desfile fue acompañado con la medianía característica de los uruguayos en el espacio público; palmas ocasionales, mate y mucho abrigo por el frío invernal de esa época del año, particularmente en el DNM del 2008.

Tabaré Vázquez fue votado en las elecciones del año 2004 por 1.121 .761 votantes, el 51\% del electorado. Precisamente esa cifra, 51\%, era la aprobación de su gestión presidencial que la encuesta de opinión pública FACTUM midió en junio 2007. Los cálculos de asistentes a las distintas ediciones del DNM varían según los medios de prensa, pero todos son coincidentes en que fue escasa. Así se puede corroborar en las fuentes fotográficas y audiovisuales. Desde tres mil personas estimadas -incluyendo no solamente al público general sino a todo el elenco gubernamental y de oficiales subalternos que fue movilizado para que concurriera- para la edición 2007 a doscientas de público general en 2010... Todo indica que la mayoría de la ciudadanía no se sintió particularmente interpelada e identificada con la propuesta. El modo de convocatoria a la ciudadanía, el libreto/trama ofertado, dice mucho también respecto al ritual conmemorativo DNM. Una puesta en escena conservadora política y estéticamente, donde el Estado revista, cuasi como tomando un examen, y aprueba, mediante sonrisas y aplausos, el paso de una representación muy frágil de la sociedad civil que se exhibe ante él, mientras otra parte de la sociedad civil -el público general- convalida mansamente la trama armada desde la producción ejecutiva.

La performance que pone en acto esta segunda secuencia resulta más comprensible al observarla en el conjunto del ritual. Primero se reconcilian los actores protagónicos Artigas y el gran mediador-, luego los secundarios. Ante la ausencia de los actores secundarios ideales en el desfile del 2008 y 2009, los desfilantes descriptos pasaron de ser actores de reparto a secundarios en cierto modo también protagónicos. La nueva generación

\footnotetext{
61 A partir de 1975 durante la dictadura hubo una explosión de conmemoraciones patrióticas esencialistas que tenían este mismo perfil compuesto de un sector civil de bandas juveniles civiles generalmente del interior (la banda juvenil de Rosario que inauguró los dos desfiles del DNM se fundó en 1974) y la sección militar. Esta política cultural implicaba la intención de "sanear" la nación de la "subversión apátrida". La única diferencia que puede encontrarse entre dichos actos y el DNM es en la composición del estrado, puesto que muchos de sus integrantes estaban en los setenta en las cárceles o el exilio. Dice Marx que "la historia se repite dos veces, primero como tragedia y después como farsa”. En otro orden, este perfil generacional de los desfilantes sintoniza con la frase de cabecera de José Mujica respecto al pasado reciente: "esto no se arregla hasta que todos los involucrados estemos muertos".

62 del Campo, op. cit., p. 66.
} 
de civiles y militares hermanados que desfila en conjunto, con entusiasmo, con alegría y, también, contribuyendo a su modo con su presencia el público general. El desfile es el momento de aceptación y celebración luego del drama. La instancia más informal y festiva dentro del rito formal. No todo puede ser solemnidad y constricción, luego del perdón colectivo hay un tiempo para desdramatizar, un espacio para la celebración. En su clasificación de los rituales Durkheim denominó a los rituales asociados a la desgracias dentro de los cuales el funeral es su máxima expresión- como ritos peculiares. Sin embargo, sostuvo que aunque tuvieran un punto de partida triste, acaban devolviendo la confianza en la vida. ${ }^{63}$

\section{Artigas presente, el último abrazo}

Sin embargo, el último momento del desfile vuelve a ser solemne. Su cierre en ambas ocasiones le correspondió a los Blandengues, una unidad militar de caballería originaria del período colonial. El propio Artigas se sumó a la misma en 1797 desde donde desertó para lanzar la revolución contra la corona española en 1811. En su etapa moderna, el Estado uruguayo instituyó al Regimiento de Caballería n ${ }^{\circ}$ en 1910 con el nombre "Blandengues de Artigas", especializado en la custodia presidencial y actividades ceremoniales en las "fechas patrias", en las que desfilan a caballo con sus insignias, banderas y una banda de músicos montados. Se caracteriza por su vestimenta denominada "Uniforme de Tradición Histórica" que tiene un diseño de estilo colonial con los colores azul marino y rojo asociados al artiguismo. En su sede tienen su propio museo llamado "Blandengues de Artigas" y una división especial dedicada al cuidado de caballos moros, puesto que una leyenda dice que Artigas murió montado en este tipo de caballo: "[el Regimiento] como custodia de la herencia del Capitán inmortal de la Unidad ha incorporado la tenencia, cuidado y presentación en paradas y desfiles militares de un caballo criollo moro como el que reclamó Artigas para su última carga a la inmortalidad."64 $\mathrm{Si}$ en el credo nacionalista esencialista todos los orientales son hijos de la Patria, los Blandengues son la descendencia más directa del linaje artiguista. En términos simbólicos, no existe ningún otro uruguayo que pueda rivalizar con ellos en cuánto a respeto al patriotismo artiguista. Custodian físicamente los restos del prócer, algunas de sus pertenencias materiales en su museo, a sus eternos fieles acompañantes -los perros cimarrones, el caballo moro-. Son la mayor materialización posible de la prolongación viva de Artigas en esta clave esencialista.

El cierre del desfile entonces son los Blandengues a caballo, y en el centro de la formación, desfila el moro, ensillado. Aparentemente nadie lo monta; o, simbólicamente, sí. Del fondo de la historia, de la inmortalidad, el espíritu de Artigas ha descendido del frío mármol para decir ipresente! En su aniversario de nacimiento, vuelve a renacer, cabalgando su eterno caballo. Es el "padre nuestro" que vuelve para abrazarse con su pueblo. Él mismo, que nunca quiso volver del Paraguay, en esta instancia tan excepcional, vuelve. Se hace presente para corresponder la súplica de su actual representante en la tierra. Artigas cierra el

63 Emile Durkheim, Las formas elementales de la vida religiosa, Colofón, México D.F., 2012, p.585.

${ }^{64}$ http://cge4.ejercito.mil.uy/armas/caballeria/museos/Artigas/Moros.htm 
desfile, es el último en responder al llamado presidencial. Un cierre circular que comenzó con la ofrenda personal del presidente hacia el prócer, culmina con un gesto recíproco por parte del prócer respondiendo a dicha invocación. Es el último gran abrazo del DNM. No hay más nada que se pueda pedir -o mucho menos- decir.

\section{Cierre}

En este trabajo se procuró conocer un evento muy particular, poco conocido y hasta olvidado, que, si bien no tuvo éxito en sus pretensiones de continuidad, considero relevante recuperarlo como experiencia histórica en tanto intento de superación de una problemática lacerante del Uruguay contemporáneo. Mi enfoque sobre el DNM privilegió su abordaje desde una perspectiva que realza su condición de teatralización política, tratamiento que prácticamente no contaba con antecedentes en las ciencias sociales locales. A nivel internacional por su parte, la mayoría de los estudios de los performances studies y antropología política del ritual, se focalizan en análisis de prácticas rituales de resistencia generadas para la contestación de los poderes establecidos por parte de grupos subordinados. En este trabajo en cambio procuré observar la teatralidad política activada desde una zona más ambigua, al examinar una política performática implementada desde el Estado, conducido por un partido político identificado con una tradición de contestación, pero que se vio enfrentado a no pocas contradicciones al asumir su nuevo lugar en la distribución del poder.

En esta sección de cierre me interesa subrayar dos temas. Primero, la inscripción del DNM en la trayectoria global de las políticas hacia el pasado reciente implementadas desde el Estado desde 1985 en adelante. Segundo, el aporte que el examen de este ritual político uruguayo particular puede efectuar al conocimiento sobre las políticas rituales hacia el pasado conflictivo reciente en la experiencia hispanoamericana.

Durante los primeros tres lustros de la post-dictadura el Estado uruguayo instauró fuertemente como un axioma la idea de que el pasado reciente se había superado, que lo verdaderamente importante era la "restauración" de la democracia, concebida como el estilo de vida y la esencia por antonomasia de la uruguayidad. Ello implicó representar al conjunto del pasado reciente como su antítesis, el lado oscuro de la identidad nacional. En el plano de la performatividad pública eso significó la hegemonía de los mitos y ritos del esencialismo democrático y la condena a toda voz que osara cuestionar ese dogma. La consecuencia fue el olvido, silenciamiento y la impunidad como política oficial estatal para los crímenes del régimen militar.

Primero, tibiamente, durante el gobierno de Jorge Batlle, y luego posteriormente con mayor vigor, durante el primer año y medio de gobierno del FA -marzo del 2005 a fines del 2006-, se colocó en el centro de la atención pública el tema de las violaciones a los derechos humanos en la dictadura como una gran herida irresuelta. Sin embargo, luego de ese gran impulso inicial, llegó el freno. Lo que pareció ser una reorientación política radical en la materia viró hacia una especie de paréntesis. En efecto, el enfoque metodológico privilegiado en este análisis, centrado en las secuencias performáticas de las puestas en escenas concretas del DNM, antes que solamente en las declaraciones, no deja lugar a 
dudas: los credos subyacentes del "nacionalismo esencialista", el "esencialismo democrático", "la nación como gran familia indivisa" y la "reconciliación cristiana" fueron los signos dominantes codificados en tales secuencias, mientras que el credo del "Nunca Más terrorismo de Estado" brilló por su ausencia.

Para comprender esta apuesta hacia el DNM desde un gobierno de izquierda, reitero que es crucial inscribirlo en la trayectoria global de las políticas estatales hacia el pasado reciente. Esta apuesta reconciliatoria resulta comprensible por la fuerza hegemónica del relato del Uruguay como "democracia modelo" a partir de la post-dictadura. La asociación de toda la izquierda -no solo de los tupamaros- desde el discurso de la derecha y el centro liberal con la deslealtad hacia la democracia y su responsabilidad principal en el origen de la violencia del pasado reciente caló hondo y fue interiorizada en una parte importante de la nueva dirigencia frenteamplista liderada por Vázquez. ${ }^{65}$ Por un lado, la convocatoria a esta especie de "gran Día de la Expiación" uruguayo fue un modo un tanto elíptico de habilitar un espacio de autocrítica desde filas de la propia izquierda. Por otro, también en la intención de dar espacio a "todas las voces" y en particular a "todas las víctimas" en esa gran convocatoria, el gobierno -y en particular Vázquez- procuró representarse como el nuevo "campeón de la democracia" disputándole a los mandatarios que le precedieron tal condición.

En un texto dedicado a revisar las teorías del ritual Paul Connerton identifica a la perspectiva freudiana, en la cual -señala-, los ritos se conciben como "el enunciado sistemáticamente indirecto, codificado en el simbolismo, de conflictos que ese rito disfraza y, en esa medida, niega". Además de la mención al famoso banquete original de "Tótem y tabú", cita en ducha tradición a Richard Wollheim quien sostiene que "muchos ritos exigen una muerte, generalmente la de un animal, aunque a veces también la muerte real o simulada de un ser humano, y sugiere que tales actos son invariablemente ejercicios de negación (...) El ritual niega, y aquellos que lo ejecutan niegan, la realidad de la agresión como impulso humano"66. Es discutible que esto sea aplicable a todo ritual, pero sin duda resulta atrayente para nuestro material empírico. El DNM gira obsesivamente en torno a cómo superar lo que se representa como el gran pecado del crimen fratricida. Para ello, en una especie de inversión de la interpretación clásica de Freud, se recurre al padre fundador del clan, pero es éste, en definitiva -como Cronos en la mitología griega-, quien termina devorándose a -al menos una parte de- sus hijos, puesto que ocupa el centro de la escena junto con el presidente- y terminan desplazando el tema del conflicto que justificaba la convocatoria al acto. El DNM termina enmascarando en la sumisión al padre fundador -y a su sucesor actual en la tierra- el asesinato de algunos de los hijos-hermanos por parte del Estado-padre. Como ser extraordinario Artigas es el único que vuelve del más allá para comunicar que todo está bien, que es el camino correcto. Precisamente la demanda de "Nunca Más terrorismo de Estado" es que simbólicamente se produzca el retorno de quienes fueron desaparecidos, que se devuelvan sus restos, recuperen su historia, se

\footnotetext{
${ }^{65}$ Cabe recordar que el FA del 2004 no era el mismo que el de décadas atrás. Al incrementar progresivamente su caudal electoral y acercarse a ser una opción real de gobierno fue moderando cada vez más su programa ideológico. El tema del pasado reciente no constituyó una excepción.

${ }^{66}$ Paul Connerton, Como as sociedades recordam, Celta Editora, Oeiras, 1999, p. 57.
} 
reconozca el modo en que fueron muertos, para que obtengan una despedida y sepultura dignas. Una demanda bien concreta, extremadamente terrenal, que contrasta fuertemente con los circunloquios verbales y el lenguaje performático del DNM. Por lo tanto, éste puede ser concebido como un gran ejercicio de negación, al decir de Wollheim. Una variante de la negación practicada desde la mito-praxis de la "restauración modelo" por el Estado en los ochenta, pero negación al fin. Esta vez, producida ejecutivamente desde la izquierda.

$\mathrm{Si}$ bien la comparación internacional no fue un objetivo explícito de la investigación, el estudio del DNM amplía el conocimiento de la apelación al rito político como recurso para procesar pasados conflictivos en la experiencia hispanoamericana. Me interesa detenerme particularmente en la noción de "ritual de reconciliación", originada en el estudio de del Campo sobre el caso chileno, y que -en el desarrollo del texto- apliqué también para el caso español. Al considerar en conjunto los ejemplos de los tres países, un primer atributo a resaltar es que mientras los eventos de Chile y España fueron específicos y únicos, el DNM se calendarizó e institucionalizó. O sea que la categoría podría desglozarse en rituales de reconciliación transicionales y aquellos que procuran mantenerse en el tiempo con una pretensión de perpetuidad -mediante su reiteración, un rasgo inherente a la propia noción de ritual-. En segundo lugar, la centralidad del credo cristiano en la estrategia de reconciliación nacional promovida por Aylwin descrita por del Campo no puede ser tan llamativa puesto que pertenecía al Partido Demócrata Cristiano; algo similar puede afirmarse respecto a Juan Carlos I en España. Pero en el caso del DNM esto si puede resultar más inesperado, puesto que tanto la tradición nacional uruguaya como partidaria del FA son fuertemente reivindicativas del laicismo. Por último, en los dos primeros países este tipo de rituales de reconciliación ocurrieron durante la propia transición -al inicio en Chile, al final en España-, en contextos políticos aún frágiles institucionalmente puesto que los actores políticos civiles y militares del régimen anterior mantenían parte del poder -más notorio en el caso chileno-. Pero en Uruguay el DNM se impulsó a veintiún años de concluida formalmente la dictadura y a diecisiete -el año 1989- en que los historiadores coinciden como el fin de la transición. Casi dos décadas después, con una democracia consolidada, con el poder militar subordinado al poder civil y sin prácticamente ninguna incidencia como actor político. Esto da cuenta que los rituales de reconciliación pueden trascender la temporalidad político-institucional hacia otro tipo de temporalidad más extensa conectada al plano simbólico.

\section{Referencias bibliográficas}

Aguilar, Paloma, Memoria y olvido de la Guerra Civil española, Alianza Editorial, Madrid, 1996. Allier Montaño, Eugenia, Batallas por la memoria. Los usos políticos del pasado reciente en Uruguay, Trilce, Montevideo, 2010.

---------- "De historias y memorias sobre el pasado reciente en Uruguay: treinta años de debates", en Caravelle, 104. 2015, 133-150. Université de Toulouse le Mirail

Connerton, Paul, Como as sociedades recordam, Celta Editora, Oeiras, 1999.

Crenzel, Emilio, La historia política del Nunca Más. La memoria de las desapariciones en Argentina, Buenos Aires, Siglo XXI editores, 2008.

da Matta, Roberto, O que faz o Brasil Brasil?, Rocco, Rio de Janeiro, 1989. 
de Giorgi, Alvaro, “¿Después de la violencia? Una reflexión sobre el caso uruguayo”, en José López Mazz, Elizabeth Anstett y Denis Merklen (eds), Editorial Banda Oriental, Montevideo, 2016, pp 3344.

Montevideo, 2014.

Sanguinetti. La otra historia del pasado reciente, Editorial Fin de Siglo, Delacoste, Gabriel, "El ochentismo" en Álvaro de Giorgi y Carlos Demasi (coord.) El retorno a la democracia. Otras miradas, Fin de Siglo Montevideo, 21-46.

del Campo, Alicia, Teatralidades de la memoria: rituales de reconciliación en el Chile de la transición, Mosquito Comunicaciones, Santiago de Chile, 2004.

Durkheim, Emile, Las formas elementales de la vida religiosa, Colofón, México D.F., 2012.

Franco, Marina, La 'teoría de los dos demonios': un símbolo de la posdictadura en la Argentina", Revista Contracorriente, NC State University, Vol. 11, No. 2, Winter 2014, pp. 22-52.

Garcé, Adolfo y Yaffé, Jaime, La era progresista, Montevideo, Fin de Siglo, 2014.

Hanna, Andrea, "El rol del productor en el teatro independiente. La producción es ejecutiva y algo más", Cuadernos del Centro de Estudios en Diseño y Comunicación, 50, Año 15 2014, pp. 75-80.

Hubert, Henri y Mauss, Marcel, "De la naturaleza y de la función del sacrificio", en Marcel Mauss, Lo sagrado y lo profano, Obras I, Barral, Barcelona, 1970.

Iglesias, Mariana, "El 'Día del Nunca Más' en Uruguay", en Bohoslavsky, Ernesto et alter (coords.) Problemas de historia reciente del Cono Sur, Vol. 1, pp. 147-169, Buenos Aires, Prometeo/UNGS, 2010.

Jelin, Elizabeth, La lucha por el pasado. Cómo construimos la memoria social. Siglo XXI, Buenos Aires, 2017.

Kertzer, David, "Rituais políticos e a transformação do Partido Comunista Italiano", Horizontes Antropológicos, 15, 15-36, Porto Alegre, 2001.

Lessa, Francesca, "¿Justicia o impunidad? Cuentas pendientes a treinta años del retorno a la democracia”, ILCEA 26, págs. 1-12, Université de Grenoble, 2016.

Marchesi, Aldo, (ed.) Ley de Caducidad un tema inconcluso. Momentos, actores y argumentos (1986-2013), CSIC - Trilce, Montevideo, 2013.

Marchesi, Aldo y Winn, Peter, "Uruguay: los tiempos de la memoria" en No hay mañana sin ayer, Peter Winn, Steve Stern, Federico Lorenz y Aldo Marchesi (editores), Montevideo, Banda Oriental, pags 121-204, 2014,

Markarian, Vania, Idos y recien llegados, 1967-1984. La izquierda uruguaya en el exilio y las redes transnacionales de derechos humanos, Ed. De la Vasija/CEIU, México, 2006.

Merenson, Silvina, Los peludos. Cultura, política y nación en los márgenes del Uruguay, Gorla, Buenos Aires, 2016.

Moreira, Constanza, Final de juego. Del bipartidismo tradicional al triunfo de la izquierda en Uruguay, Montevideo, Trilce, 2004.

Nunca Mas. Informe de la Comisión Nacional sobre la desaparición de personas, Buenos Aires, EUDEBA, $1^{\mathrm{a}}$ ed, 1984.

Perelli, Carina y Rial, Juan, De mitos y memorias políticas, Montevideo, 1986.

Reinbold, Jenna, Seeing the myth in Human Rights, University of Pennsylvania Press, Philadelphia, 2017.

Rico, Alvaro, (Coord.) Investigación histórica sobre Detenidos Desaparecidos. En cumplimiento del artículo 4 de la Ley 15.848, Montevideo, Presidencia de la República, 2007.

---------- Cómo nos domina la clase gobernante. Orden político y obediencia social en la democracia posdictadura. Uruguay 1985-2005. Montevideo, Trilce, 2005

Salles,Vania y Tuirán, Rodolfo, "Mitos y creencias sobre la vida familiar", Revista Mexicana de Sociología, 58-2, 1996. 
Sahlins, Marshall, Islas de Historia. La muerte del capitán Cook. Metáfora, antropología e historia, Barcelona, Gedisa, 1997.

Salvi, Valentina, “'Todos somos víctimas'. Transformaciones en la narrativa de la 'reconciliación nacional' en la Argentina", en José Luis Lanata (comp.) Prácticas genocidas y violencia estatal en perspectiva transdiciplinar, Universidad Nacional de Río Negro, San Carlos de Bariloche, 2014. Sikkink, Kathryn, "From pariah State to global protagonist: Argentina and the struggle for International Human Rights", Latin American politics and society 1, 2008, p. 1-29.

SERPAJ, Uruguay nunca más: informe sobre la violación a los derechos humanos (1972-1985), 1989.

Smith, Anthony, "The myth of the "modern nation" and the myths of nations", Ethnic and Racial Studies 11, v.1, 1988.

Yaffé, Jaime Al centro y adentro. La renovación de la izquierda y el triunfo del Frente Amplio en Uruguay, Montevideo, Linardi y Risso, 2005.

\section{Fuentes documentales y digitales}

prensa escrita nacional (diarios La República, El Observador, El País; semanario Búsqueda) 20062011.

archivo.presidencia.gub.uy registro oficial de Presidencia de la República 2006-2011.

www.geipar.udelar.edu.uy, GEIPAR - UDELAR.

Espectador.com, "El Día del Nunca Más: una pifia del gobierno" http:www.espectador.com/ politica/ 96383/ el-dia-del-nunca-mas-una pifia-del gobierno. 28 de mayo de 2007.

http://www.vatican.va/ archive/ catechism_sp/p2s2c2a4_sp.html

www.subrayado.com.uy/noticias/24554/el-dia-del-nunca-mas-que-quedo-para-el-olvido.

http://cge4.ejercito.mil.uy/armas/caballeria/museos/Artigas/Moros.htm 